\title{
Interventions to Prevent Obesity in Mexican Children and Adolescents: Systematic Review
}

\author{
Magaly Aceves-Martins ${ }^{1}$ (1) - Lizet López-Cruz ${ }^{2} \cdot$ Marcela García-Botello $^{3} \cdot$ Yareni Yunuen Gutierrez-Gómez ${ }^{4}$. \\ Carlos Francisco Moreno-García ${ }^{5}$
}

Accepted: 1 October 2021 / Published online: 2 November 2021

(c) The Author(s) 2021

\begin{abstract}
The prevalence of overweight and obesity has been rising among Mexican children and adolescents in the last decades. To systematically review obesity prevention interventions delivered to Mexican children and adolescents. Thirteen databases and one search engine were searched for evidence from 1995 to 2021. Searches were done in English and Spanish to capture relevant information. Studies with experimental designs, delivered in any setting (e.g., schools or clinics) or digital domains (e.g., social media campaigns) targeting Mexican children or adolescents ( $\leq 18$ years) and reporting weight outcomes, were included in this review. In addition, the risk of bias was appraised with the Effective Public Health Practice Project Quality Assessment Tool. Twenty-nine studies with 19,136 participants (3-17 years old) were included. The prevalence of overweight and obesity at baseline ranged from 21 to $69 \%$. Most of the studies $(89.6 \%)$ were delivered in school settings. The duration ranged from 2 days to 3 school years, and the number of sessions also varied from 2 to 200 sessions at different intensities. Overall, anthropometric changes varied across studies. Thus, the efficacy of the included studies is heterogeneous and inconclusive among studies. Current evidence is heterogeneous and inconclusive about the efficacy of interventions to prevent obesity in Mexican children and adolescents. Interventions should not be limited to educational activities and should include different components, such as multi-settings delivery, family inclusion, and longer-term implementations. Mixed-method evaluations (including robust quantitative and qualitative approaches) could provide a deeper understanding of the effectiveness and best practices.
\end{abstract}

Keywords Obesity $\cdot$ Prevention $\cdot$ Children $\cdot$ Adolescents $\cdot$ Mexico

\section{Introduction}

The prevalence of overweight and obesity is a major international public health problem and has nearly doubled in the last three decades, especially among children and

Magaly Aceves-Martins

magaly.aceves@abdn.ac.uk

1 The Rowett Institute of Nutrition and Health, University of Aberdeen, Foresterhill, Aberdeen AB25 2ZD, UK

2 Universidad Europea del Atlántico, Parque Científico Y Tecnológico de Cantabria, C/Isabel Torres 21, 39011 Santander, Spain

3 Universidad de Monterrey, Zona Valle Poniente, Av. Ignacio Morones Prieto 4500, 66238 San Pedro Garza García, N.L, Mexico

4 Nutrition and Wellbeing Department, Tecnológico de Monterrey, Col. Ejidos de Huipulco, Tlalpan, Mexico City, Mexico

5 School of Computing, Robert Gordon University, Garthdee House, Garthdee Road, Aberdeen AB10 7QB, Scotland, UK adolescents (Global Obesity Observatory, 2019). Excess body fat in children and adolescents can lead to various clinical conditions and psychosocial disorders that might significantly reduce their quality of life. Moreover, children and adolescents with obesity are likely to maintain their weight status into adulthood, increasing their risk of developing chronic diseases, contributing to increased morbidity and premature mortality (WHO, 2012; Wang \& Lim, 2012).

Mexico is an upper-middle-income Latin-American country where obesity levels have been increasing alarmingly in the last decades (Aceves-Martins et al., 2016a; Astudillo, 2014). Specifically, overweight and obesity rates have increased in the $<18$ years old population. According to the latest results from the National Health and Nutrition Survey (ENSANUT, 2018), it is estimated that $8.2 \%$ of infants ( $0-4$ years), $35.6 \%$ of school-age children (5-11 years), and almost $40 \%$ of adolescents (12-19 years) have overweight or obesity in Mexico. In addition, the Global Obesity Observatory (2019) suggests that Mexico has one of the highest prevalence of obesity among children and adolescents worldwide. Furthermore, 
according to the Organisation for Economic Co-operation and Development estimations, obesity rates will continue to rise in Mexico if no effective strategies are implemented (OECD, 2017). Likewise, some economic models have estimated that childhood obesity in Mexico's economic impact between 2006 and 2050 will be much higher than what the health care system can stand, jeopardising the general population's health care and wellbeing (Garduño-Espinosa et al., 2008; OrtegaCortés, 2014).

Most of the published systematic reviews on childhood obesity prevention include only English publications (Ash et al., 2017; Liu et al., 2019; Tamayo et al., 2021; Ward et al., 2017) or evidence from high-income countries (Tamayo et al., 2021; Wang et al., 2015), excluding valuable evidence from non-English speaking low- or middle-income countries such as Mexico. The "Childhood and adolescent Obesity in MexicO: evidence, challenges and opportunities" (COMO) Project intend to synthesise and use data to comprehend the extent, nature, effects, and costs of childhood and adolescent obesity in Mexico (Aceves-Martins, 2021a, b, c). This systematic review is part of the COMO project, and it aims to identify and evaluate studies implemented in Mexico to prevent obesity among children and adolescents ( $<18$ years).

\section{Methods}

This project's systematic review is registered in The International Prospective Register of Systematic Reviews (Registration number CRD42019154132) (PROSPERO, 2021). In addition, this review is reported according to Preferred Reporting Items for Systematic Reviews and Meta-analyses guidelines (PRISMA, 2021). The research question and inclusion/exclusion criteria were established following the Population, Intervention, Comparison, Outcomes, Study design (PICOS) framework.

\section{Electronic Searches}

A sensitive search was developed to include index terms, freetext words, abbreviations, and synonyms to combine the key concepts for this review. Terms such as "overweight," "obesity," "child," "adolescent," "intervention," "program," and "Mexico" were included in the strategy with different term variation/synonyms and Boolean connectors to capture relevant publications. The databases searched included MEDLINE, EMBASE, the Cochrane Library, Global Health Library, LILACS, CINAHL, CAB abstracts, ERIC, PsycINFO, ScienceDirect, Scopus, AGRICOLA, and SciELO Citation Index. Also, the search engine Google Scholar was used to identify relevant studies. When possible, searches were also done in Spanish to capture relevant references. Conference abstracts and poster presentations were included if the inclusion criteria were met. Also, reference lists of the included studies were scrutinised for additional publications, and experts in the field were contacted for additional relevant reports. Searches were done in January 2020 and updated in January 2021.

\section{Selection Criteria}

Reports from 1995 onwards were included in this review to focus on information conducted under current epidemiological and environmental circumstances of child and adolescent obesity in Mexico. All searches were restricted to English, Spanish, or Portuguese language publications to capture reports from the most widespread languages spoken in the Americas. Following the PICOS framework, our inclusion/ exclusion criteria were:

\section{Population}

Children and adolescents from zero to 18 years old (mean age at the start of the study) from any ethnicity or gender living in Mexico were included. Studies that involved parents, caregivers, or related stakeholders (e.g., teachers or health carers) were included only if the outcomes were measured in children or adolescents. Studies evaluating the treatment (i.e. only including participants with obesity) were excluded from this review. Mexican children living in different countries were excluded to better conceptualise the obesity problem within their sociodemographic characteristics, avoiding confounding information inherent to the migration phenomena. Likewise, studies that analysed children's severe conditions (e.g. HIV, cancer, down syndrome), premature babies and pregnant adolescents were excluded.

\section{Intervention}

Obesity prevention or lifestyles interventions delivered among Mexican children or adolescents were considered.

\section{Outcomes}

Since weight and weight-related measures are indispensable for the evaluation effectiveness of interventions related to child and adolescent overweight and obesity (Green et al., 2012), weight-related outcomes (i.e., weight, BMI, or BMI $\mathrm{z}$-score change) were considered in this review as primary outcomes. Because of the studies' nature, any other outcome related to lifestyle changes (i.e., dietary, PA, behavioural outcomes) was also recorded as secondary outcomes.

\section{Study Design}

Any experimental or quasi-experimental studies designs were considered. In addition, interventions delivered in any setting 
(e.g. home-based, school-based, clinic-based, communitybased, leisure centres) or digital domains (e.g. social media interventions) were considered.

\section{Data Extraction}

Titles, abstracts, and relevant full-texts were screened by two reviewers (LL, MGB) and 100\% checked by a third reviewer (MA-M). Two reviewers (MA-M and LLC) extracted data from intervention studies independently. In case of any disagreement, a third author was contacted (YG).

A data extraction form was created based on the Effective Public Health Practice Project Quality Assessment Tool (EPHPP, 2010) for quantitative studies and the PICOS framework. The template for intervention description and replication (TIDieR, 2021) checklist items were also included in the extraction form. Critical components of the interventions were extracted and categorised as a) Nutritional (i.e., studies including diet prescriptions or nutritional advice); b) PA (i.e., studies including PA practise or PA advice); c) behavioural or psychological (i.e., studies including counselling, or behavioural therapy); and d) environmental changes (i.e., environment changes to promote a weight change among participants). Any strategy or framework used in the design of the interventions was also recorded.

\section{Quality and Risk of Bias Assessment}

Following the Cochrane Handbook's recommendation about systematic reviews of health promotion interventions (Armstrong et al., 2011), the EPHPP (2010) Assessment Tool for Quantitative Studies was used. This tool produces an overall methodological rating (i.e., strong, moderate, or weak evidence) and comprises eight categories: selection bias; study design; confounders; blinding; data collection methods; withdrawals and drop-outs; intervention integrity; and analysis. According to the quality assessment tool's guidelines for each category, the scores were added, producing a global rating. In addition, the funding source and reported conflicts of interest were also extracted. Two reviewers (MA-M and LLC) evaluated each included study independently and then agreed. In case of any disagreement, a third author was contacted (YG).

\section{Data Synthesis}

A meta-analysis was not feasible because of the heterogeneity among the included studies and the lack of outstanding quality Randomised Controlled Trials [RCTs]. Hence, a narrative synthesis was conducted. The data obtained from the included studies were narratively synthesised, and relevant characteristics were tabulated. According to the type of study (i.e. studies including a control group and cohort studies without control groups), results were reported in the text. In addition, textual descriptions of studies and reported statistical significance were recorded and tabulated. Quality assessment was included in the synthesis.

\section{Results}

Our searches identified 9828 references, from which 1432 were retrieved for full-text review. Thus, overall, 886 references were included in the COMO database. From these, 58 studies (presented in 74 publications) were identified. From these, 29 studies (presented in 43 publications) met the inclusion criteria (Fig. 1). Nearly half of the studies (14/29) were published in Spanish, and the rest in English. Also, less than half (12/29) were published in Mexican journals.

From the 29 studies included, four (13.7\%) (Levy et al., 2012a, b; Macias et al., 2014; Mejia et al., 2016; MoralesRuán et al., 2014) were conference abstracts. Sixteen studies (55.2\%) included control groups (seven [24.1\%] were RCTs, one [3.4\%] pilot RCT, eight [27.5\%] were controlled trials), and 13 (44.8\%) were cohorts (11 [37.9\%] were single cohorts, and two [6.8\%] were cohort analytic, including two intervention groups) (Table 1).

Overall, this systematic review includes data from 19,136 participants (from 3 to 17 years old) recruited from 13 Mexican states (out of 32) (Fig. 2). Only Caballero-García et al. (2017) implemented a multi-site intervention that included pupils from different states across Mexico. The prevalence of overweight and obesity at baseline ranged from 21 to $69 \%$ across included studies. All the studies targeted and included both males and female participants. Most of the studies (89.6\%) were delivered in school settings, two (MartínezAndrade et al., 2014; Rodriguez-Ventura et al., 2018) in public clinics, and one (Zacarías et al., 2019) in a community setting. One study (Martinez-Andrade et al., 2014) was delivered among a preschool population, 22 studies among a school-age population (6-12 years), and six among adolescents (13-18 years). The principal characteristics of the included studies are presented in Table 1.

The design and implementation of the included studies varied widely. Some studies $(13 ; 44.8 \%)$ included educational interventions, some others $(5 ; 17.2 \%)$ included PA practise as an intervention, three (10.3\%) included both educational intervention and PA practise, and one (3.4\%) incorporated a school breakfast provision besides an educational intervention and PA practise. Elizondo-Montemayor et al. (2014) delivered a social media campaign plus a non-mandatory PA masterclass as part of the study. Ríos-Cortázar et al. (2013) used children's narratives to reconstruct the school's environment towards creating a healthier school atmosphere. Martínez-Andrade et al. (2014) and Salazar Vázquez et al. 
Fig. 1 PRISMA flowchart

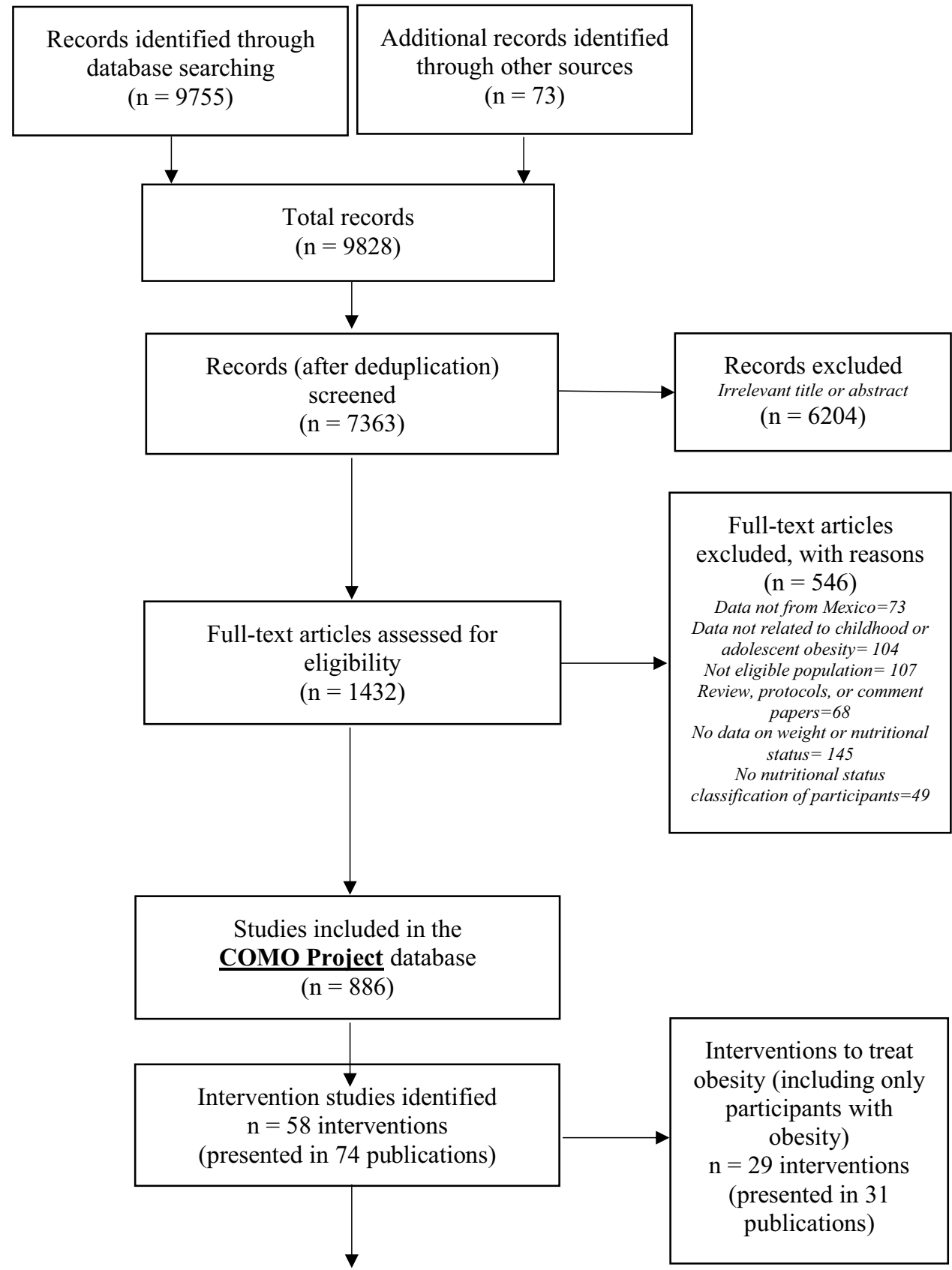

Intervention studies to prevent or revert overweight and obesity in children and adolescents with or without obesity

$\mathbf{n}=\mathbf{2 9}$ interventions (presented in 43 publications)

(2016) included solely motivational counselling. RodriguezVentura et al. (2018) included a multidisciplinary clinical intervention. Zacarías et al. (2019) delivered a community intervention aiming to change children's weight but intervening mothers. However, this was not the only study including parents or other family members. Twelve studies $(41.3 \%)$ included parents or siblings as active participants of the activities delivered to children (Table 1).

Overall, the components of the included studies also varied. Most of the studies $(26 ; 89.6 \%)$ included a nutritional 


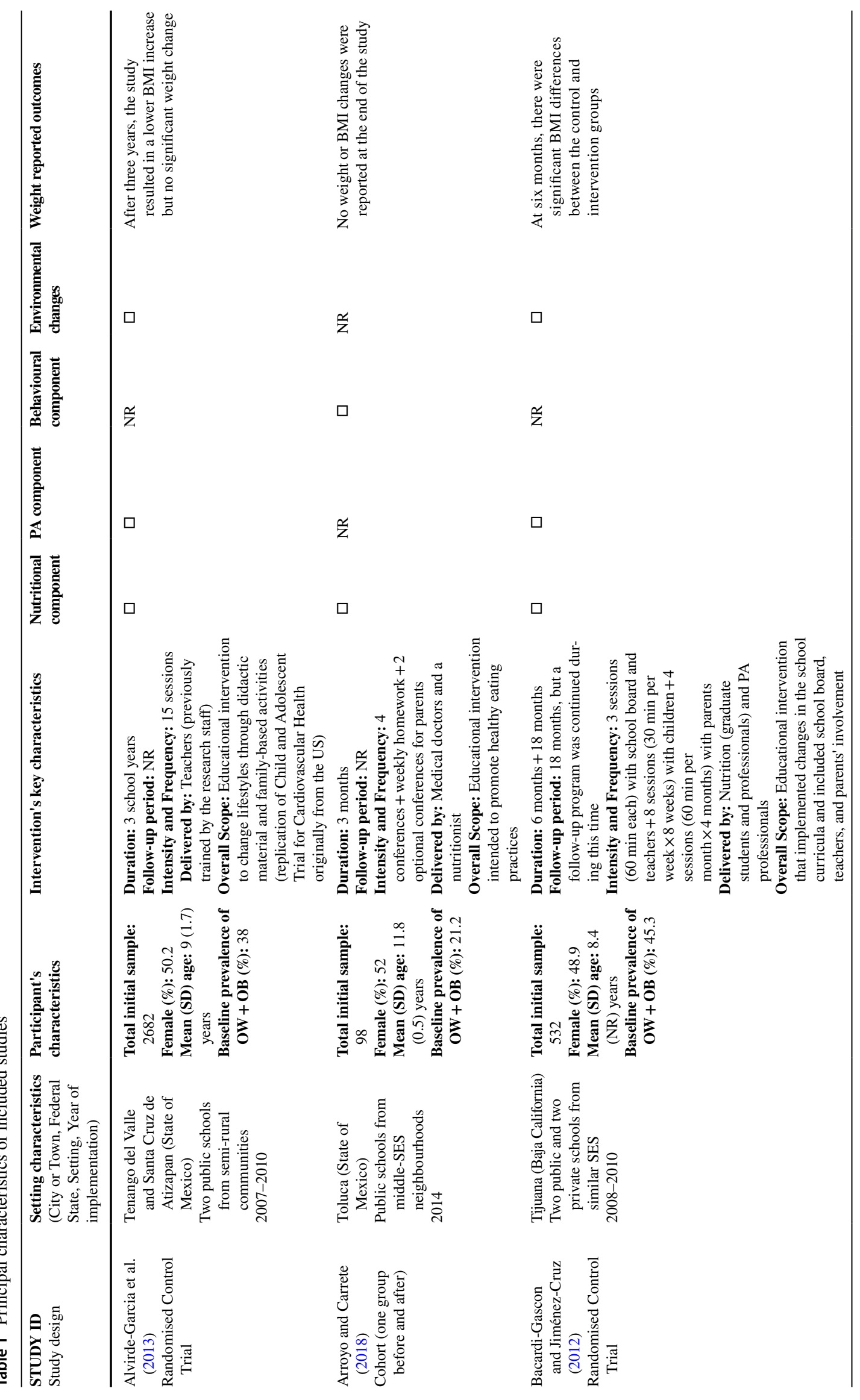




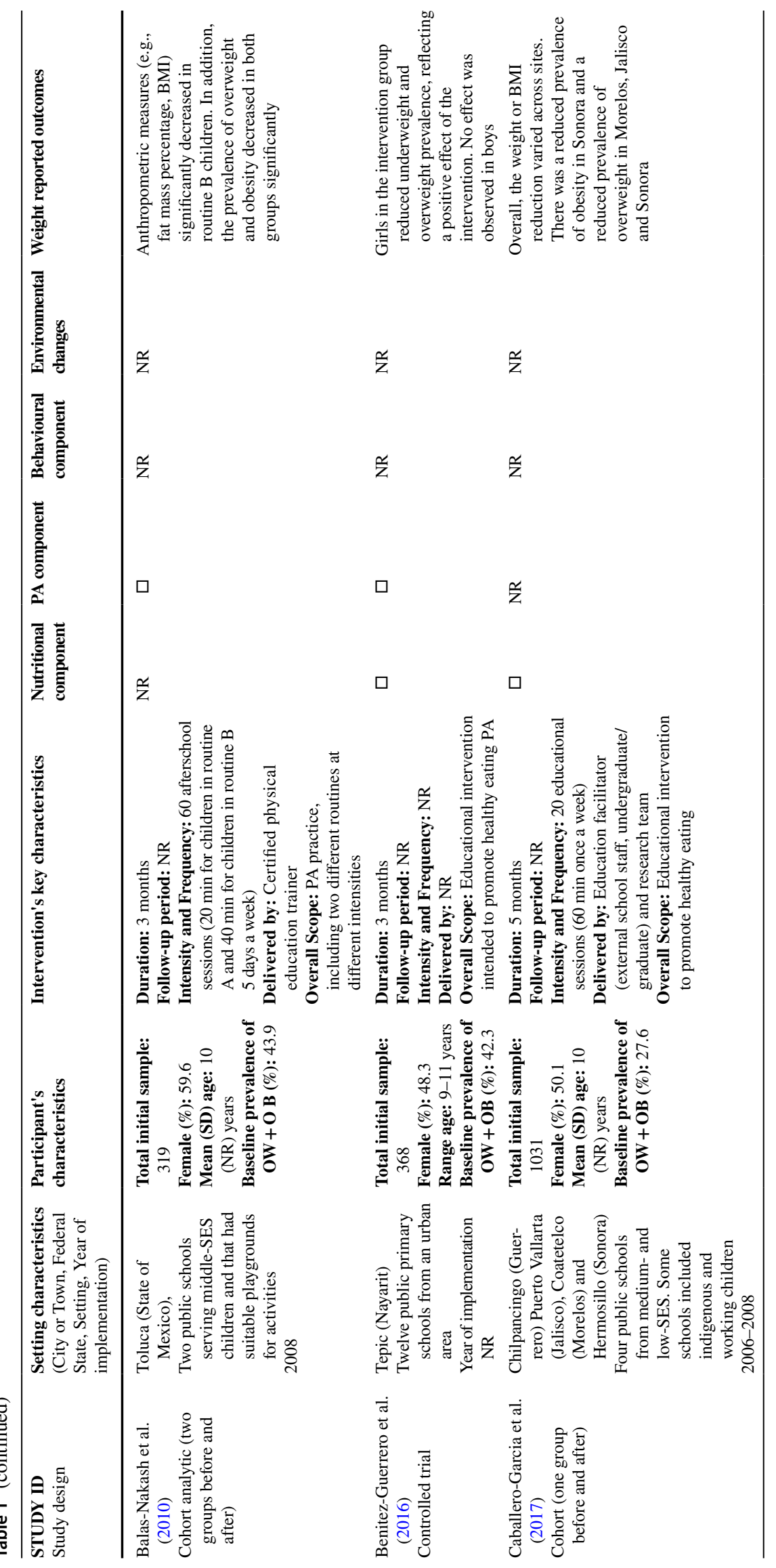




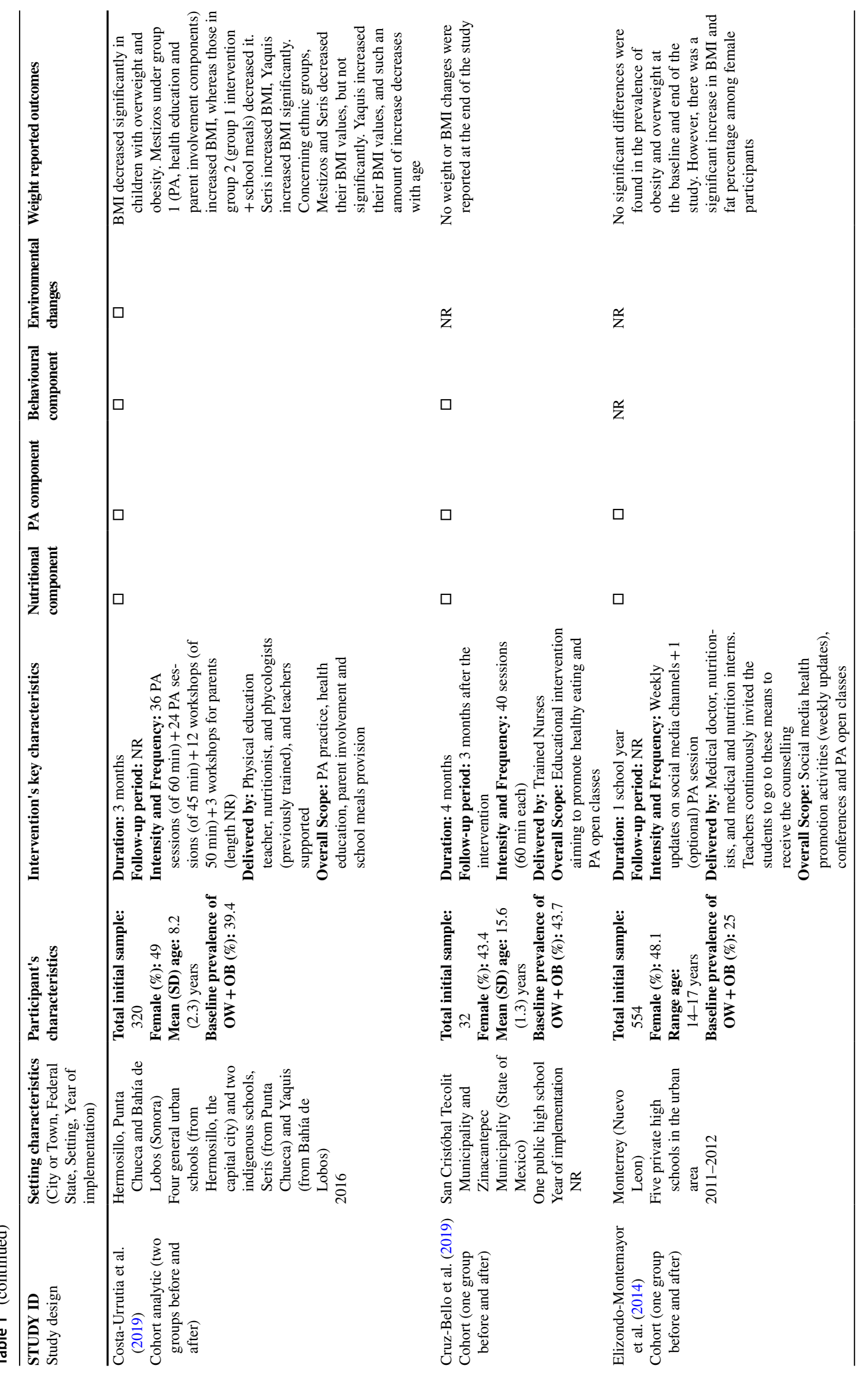




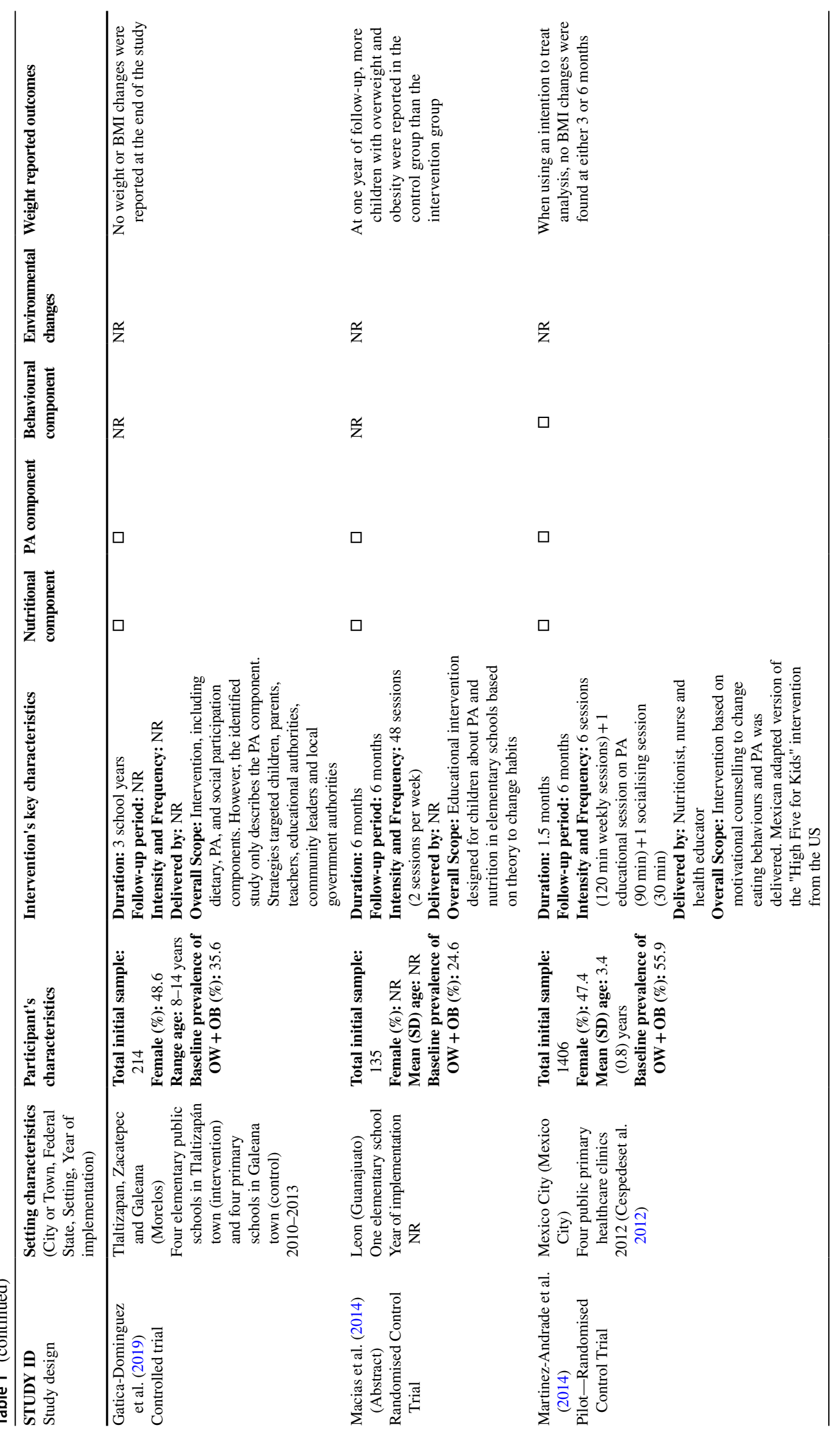




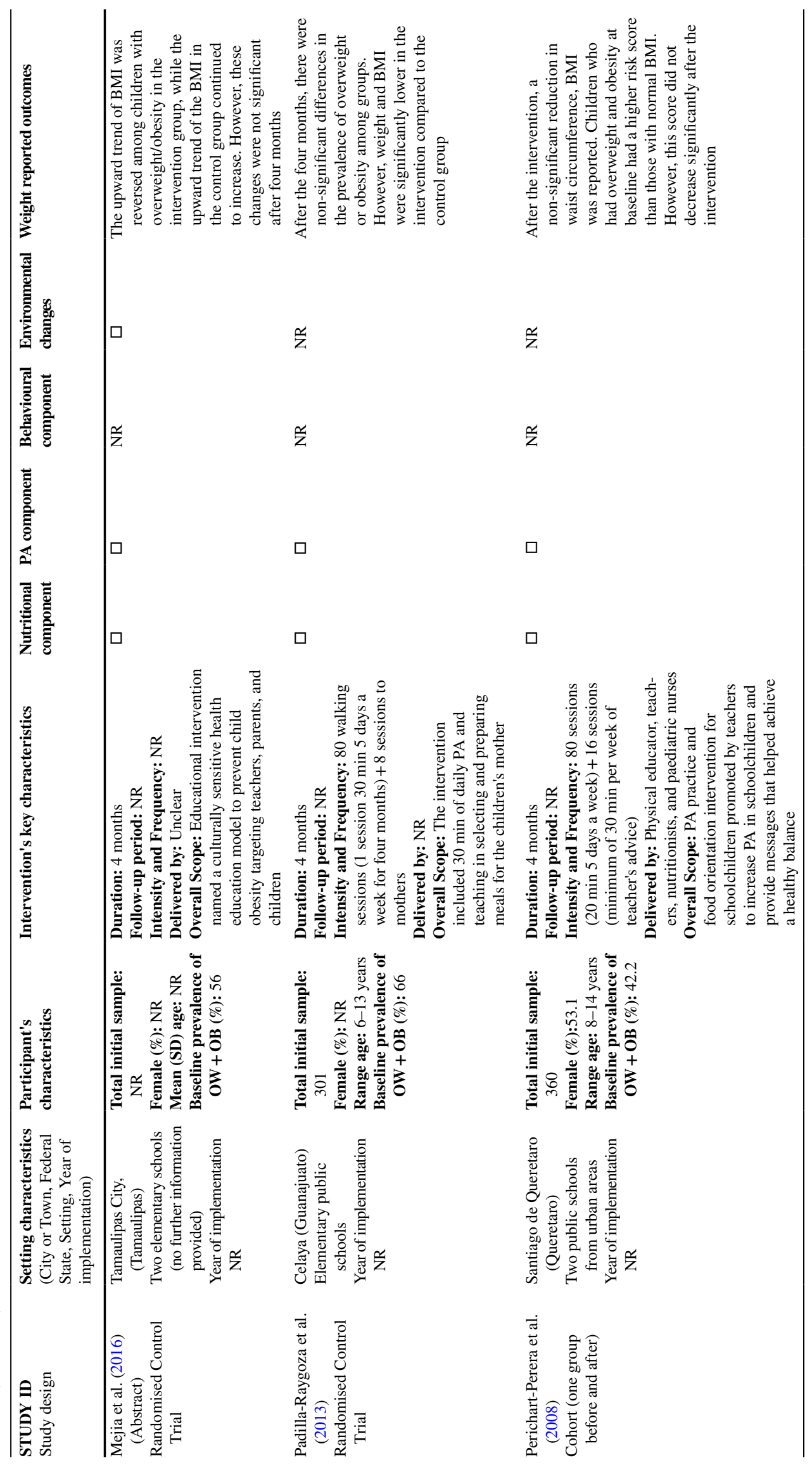




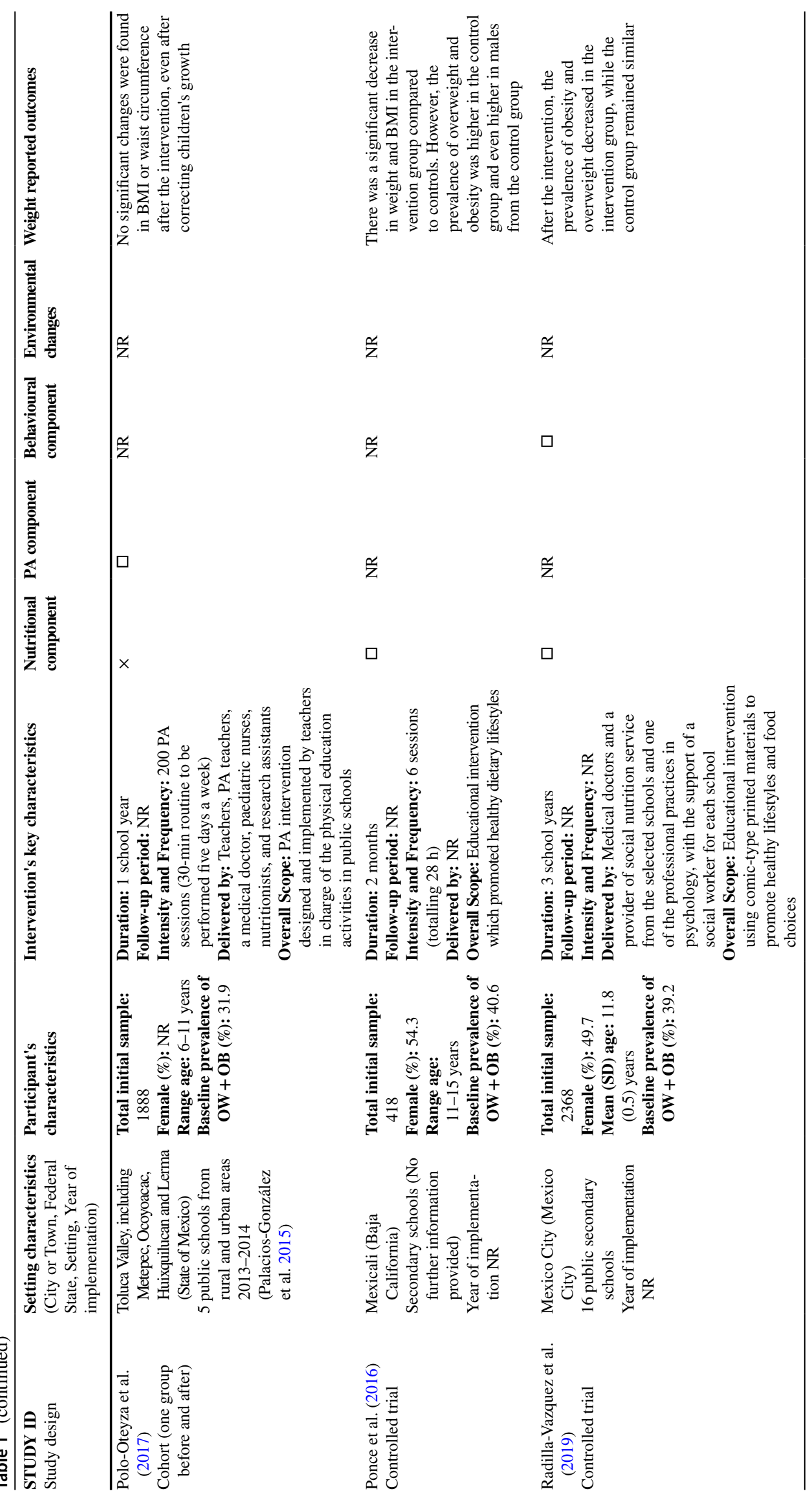




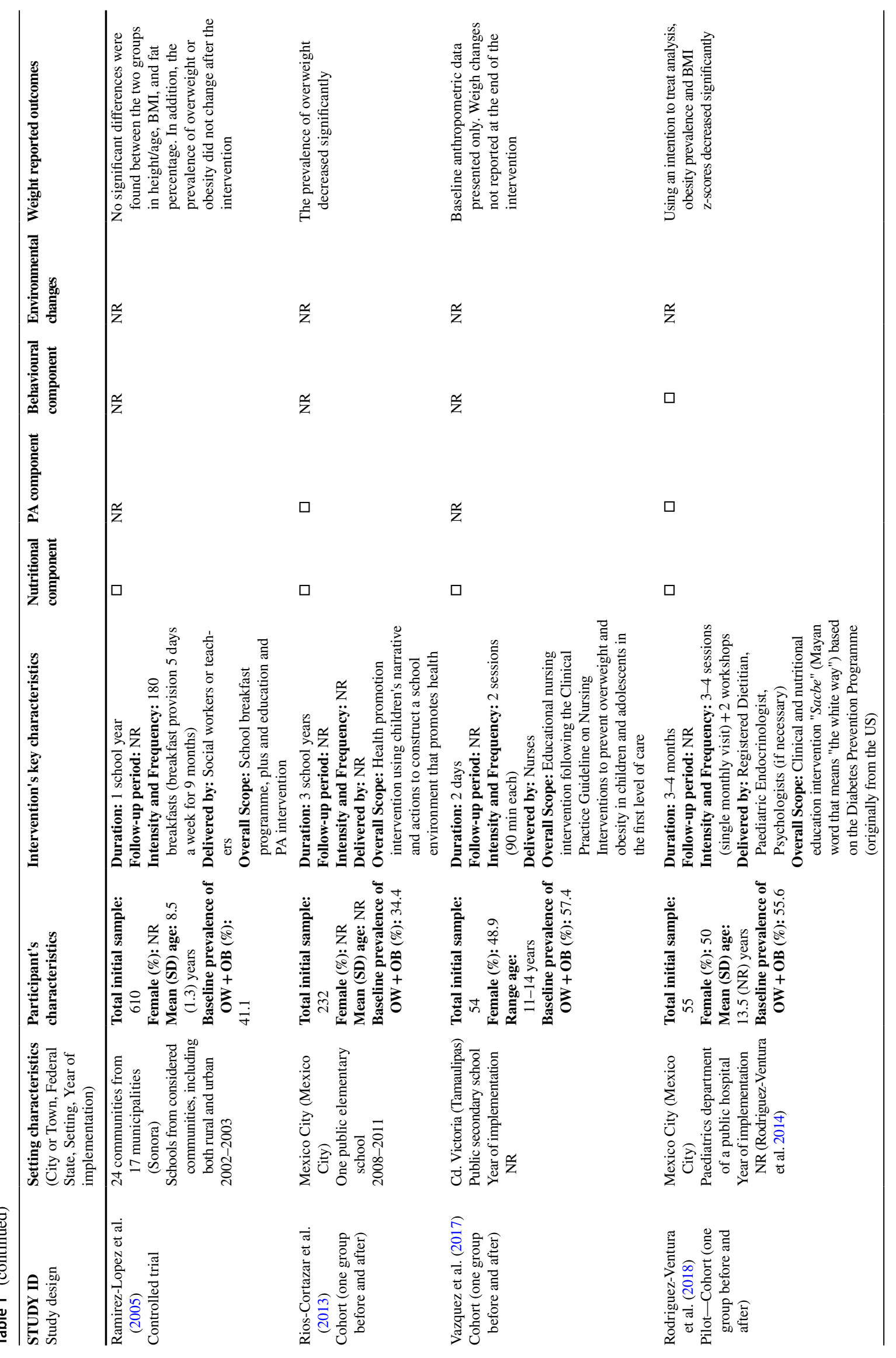




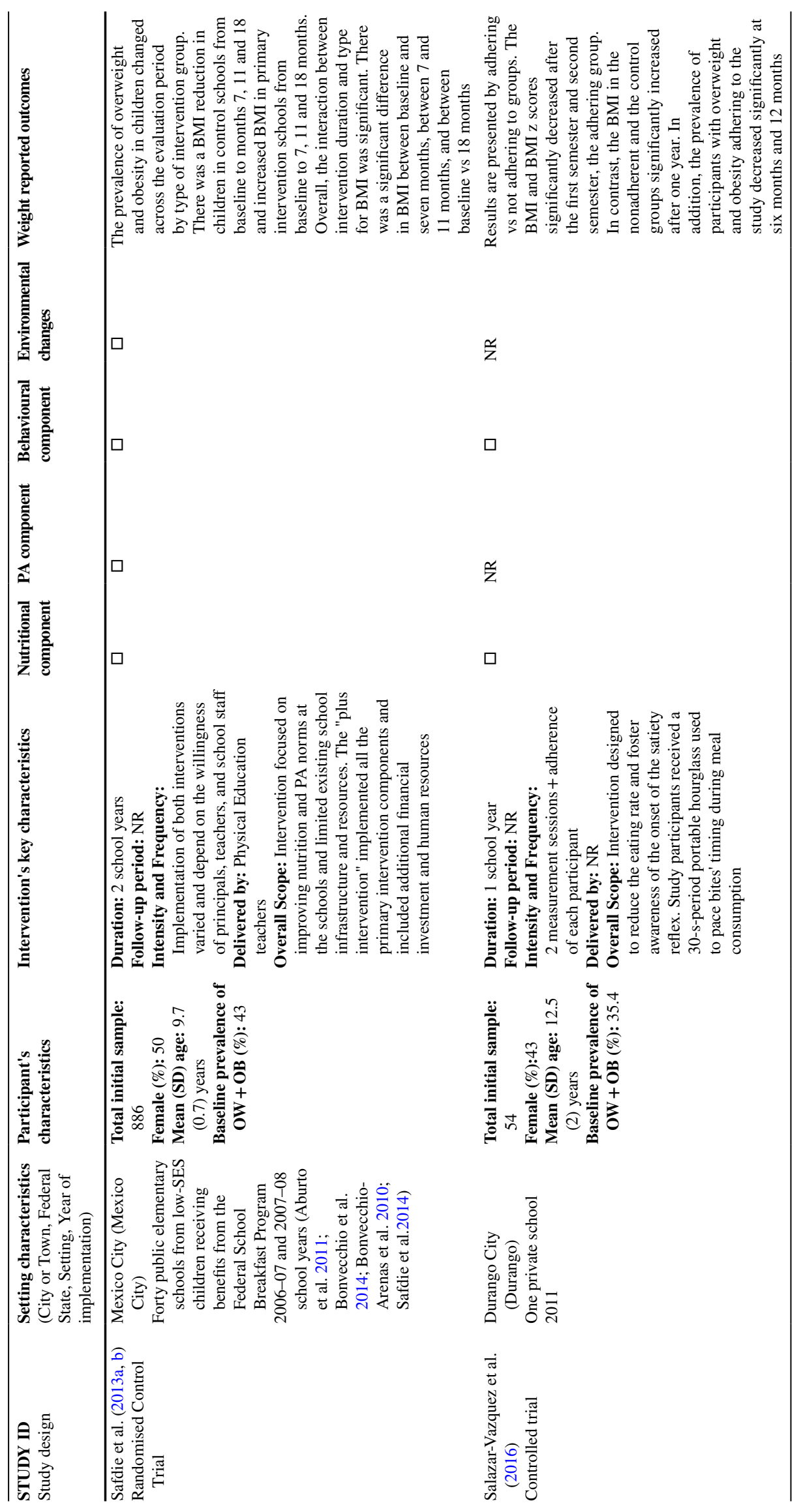




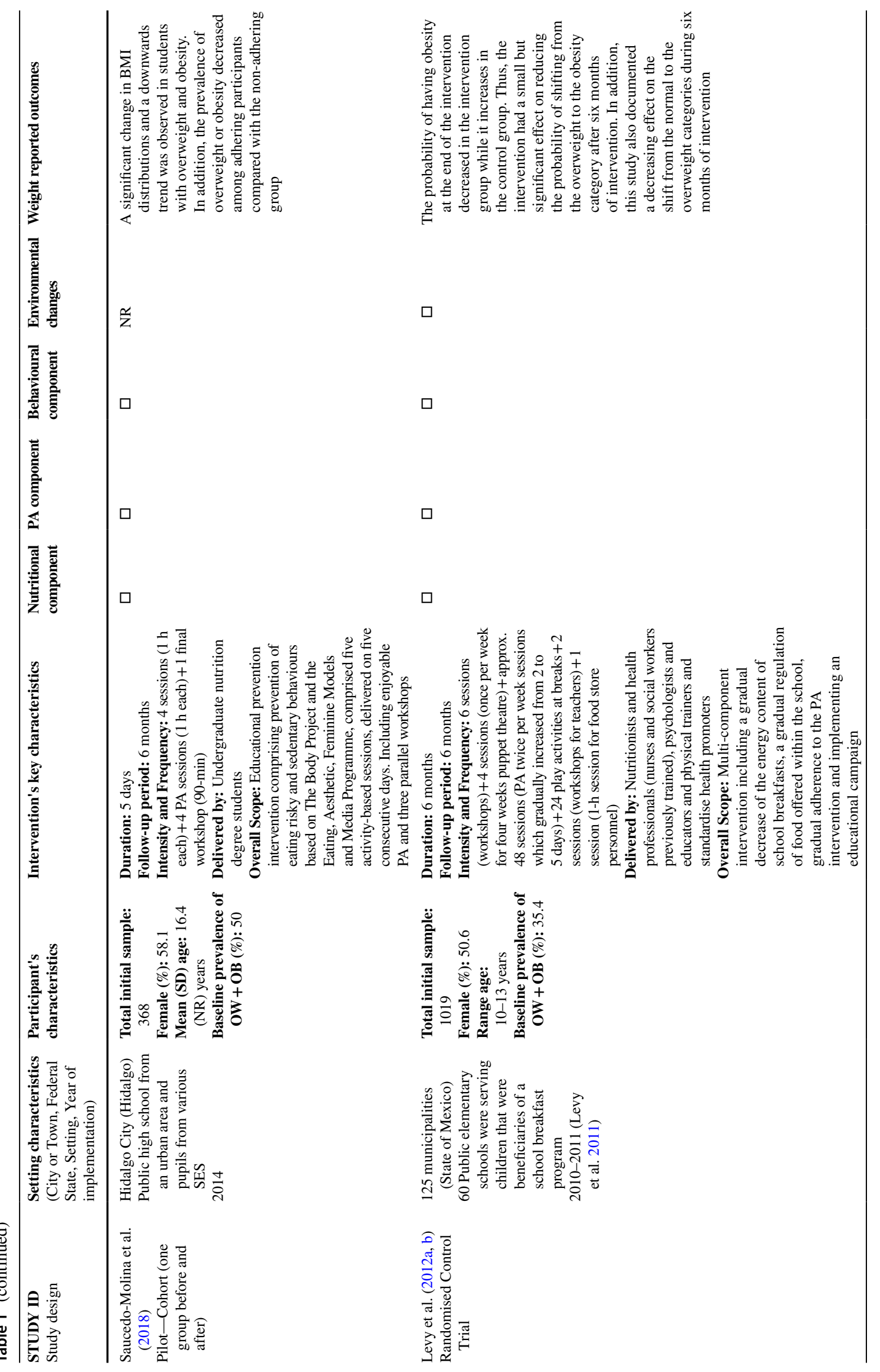




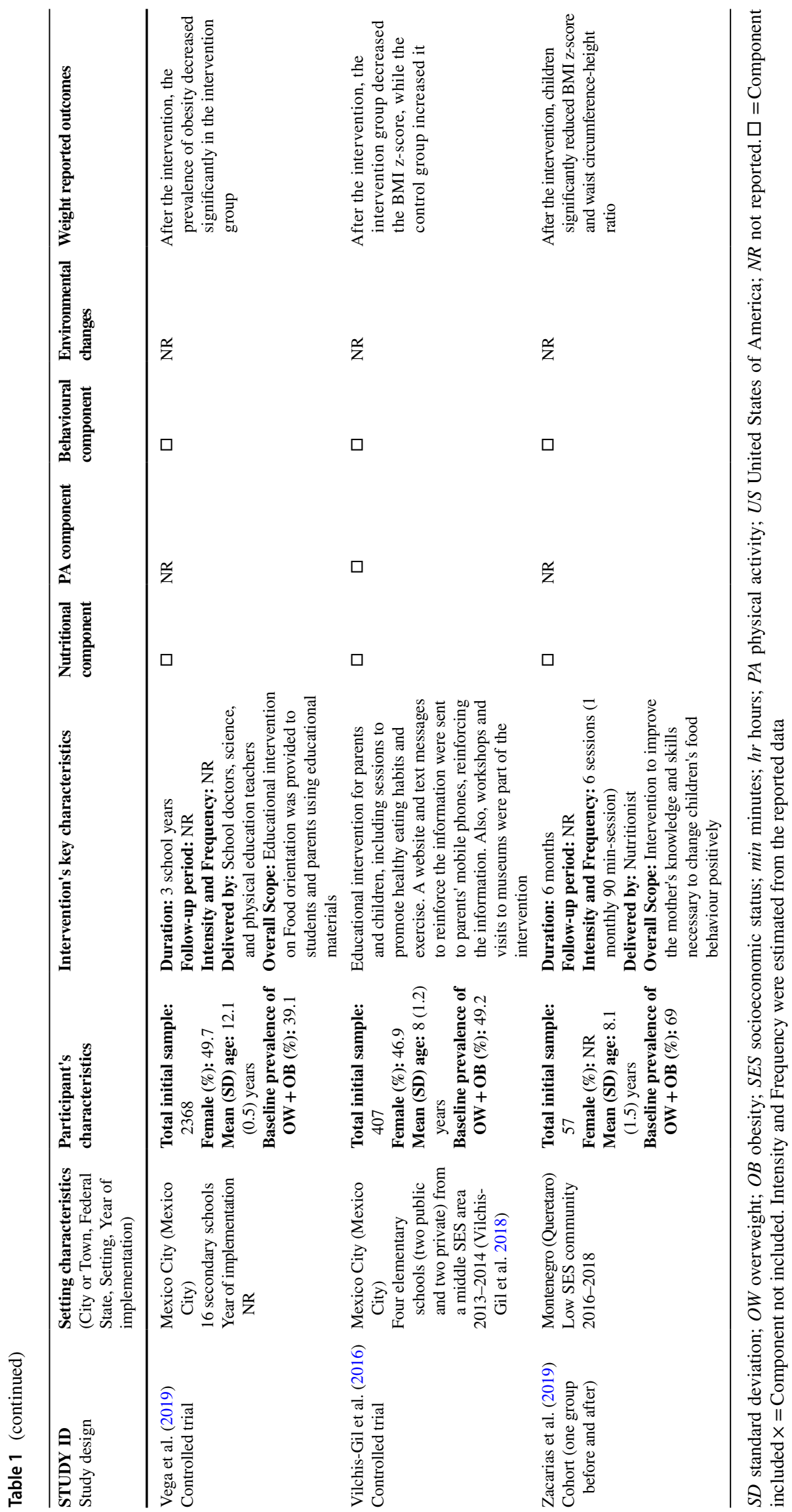



the included interventions
Fig. 2 Map from the origin of

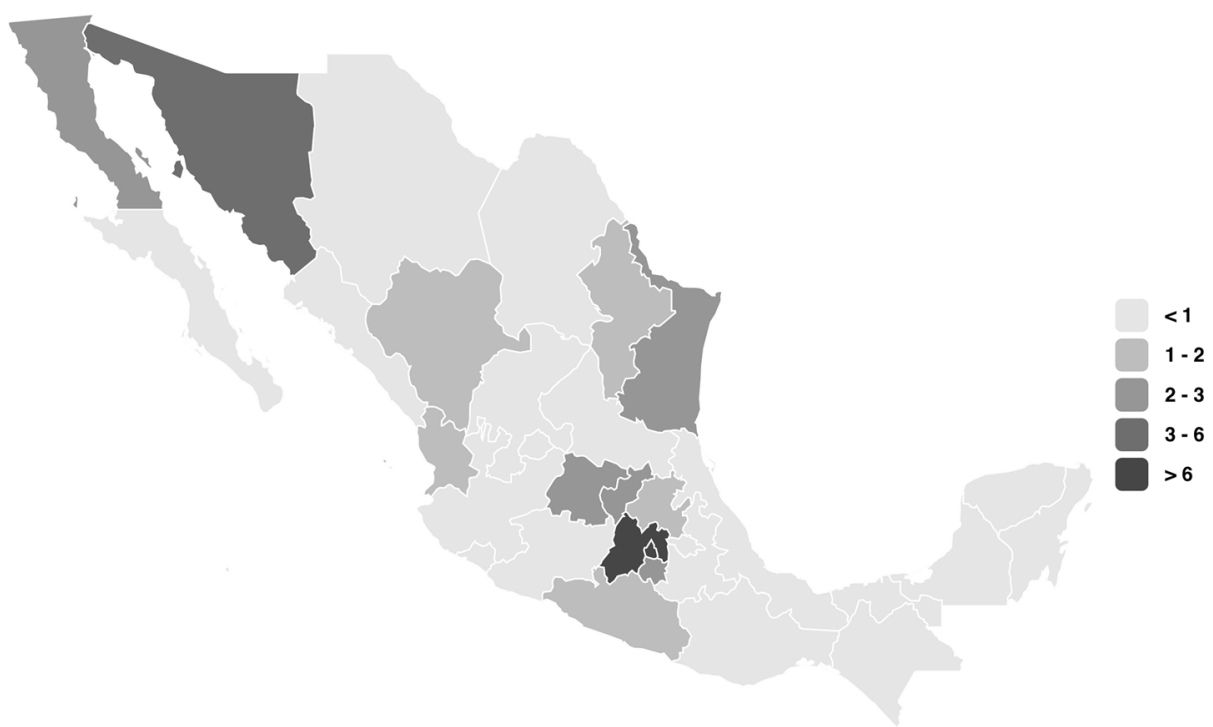

or dietary component. Some studies $(17 ; 58.6 \%)$ included a PA component, and less $(13 ; 44.8 \%)$ included behavioural or physiological components. Few studies $(6 ; 20.7 \%)$ considered environmental or setting changes (e.g., modifications to the school food stores or improving the school's infrastructure) (Table 1). Only Costa-Urrutia et al. (2019), Safdie et al. (2013a, b) and Levy et al. (2012a, b) included all the components considered in this review (i.e. considered in the studies a nutritional, PA, behavioural and an environmental change). The studies' duration varied, ranging from 2 days to 3 school years. The frequency and intensity of the interventions (calculated from the reported data) also varied from 2 to 200 sessions with different intensities (Table 1). Further details on the components and characteristics of each study are provided in Supplementary Information 1.

Some studies $(9 ; 31.0 \%)$ reported using a framework or theory during the intervention's design and implementation: Bacardí-Gascon and Jiménez-Cruz (2012) used Bronfenbrenner's Ecological Model; Gatica-Domínguez et al. (2019) used the Booth's Eco-social Model; Safdie et al. (2013a, b) used the Ecological Principles summed to a Theory of Planned Behaviour, Social Cognitive Theory, and a Health Belief Model; Zacarías et al. (2019) used the Theory-Informed Model, Social Cognitive Theory and Interpersonal Models; Martínez-Andrade et al. (2014) used the Chronic Care Model with Family-Centred Approach; Rodriguez-Ventura et al. (2018) used the Sociocultural and Precede-Proceed Models; Arroyo and Carrete (2018) used the Protection Motivation Theory; and Mejia et al. (2016) used the Psycho-Pedagogical Theory (including Social Cognitive Theory and Positive Psychology). Macias et al. (2014) reported using a "theory to change habits," but no further detail was provided. Also, some studies reported using different delivery techniques. For instance, Costa-Urrutia et al. (2019), Saucedo-Molina et al. (2018) and Levy et al. (2012a, b) used participatory actions to deliver the activities or other psychoeducational strategies, such as peer-learning or empowerment, triggering technique and experience-based technique.

\section{Changes in Anthropometric Outcomes}

Results were heterogeneous among studies that included a control group $(n=16)$. No statistically significant $(p<0.05)$ the studies across the evaluation period or between groups (Alvirde-García et al., 2013; Gatica-Domínguez et al., 2019; Martínez-Andrade et al., 2014; Ramírez-López et al., 2005). Macias et al. (2014) and Mejia et al. (2016) reported that the upward BMI trend was reversed among children with overweight/obesity in the intervention group, while the control group's upward BMI trend continued to increase. However, no statistical significance test was presented. Some studies $(9 / 16)$ found a significant statistical $(p<0.05)$ change in either weight or BMI (Padilla-Raygoza et al., 2013; Ponce et al., 2016; Safdie et al., 2013a, b; Vilchis-Gil et al., 2016) or obesity prevalence (Bacardí-Gascon \& JiménezCruz, 2012; Perez-Morales et al., 2011; Radilla-Vazquez et al., 2019; Levy et al., 2012a, b; Vega et al., 2019) across the evaluation period and between groups. Benitez-Guerrero et al. (2016) reported only BMI effects among girls from the intervention group, but not in boys or the control group. Salazar-Vazquez et al. (2016) reported statistically significant $(p<0.05)$ BMI changes only in those participants from the intervention group that adhere to the intervention.

Results were also heterogeneous among cohort studies $(n=13)$. No statistically significant BMI or obesity prevalence changes were reported in 6/13 of the studies (Arroyo \& BMI or obesity prevalence changes were reported in $4 / 16$ of 
Carrete, 2018; Cruz-Bello et al., 2019; Elizondo-Montemayor et al., 2014; Perichart-Perera et al., 2008; Polo-Oteyza et al., 2017; Vazquez et al., 2017). But some studies (5/13) reported significant reductions in BMI (RodriguezVentura et al., 2018; Saucedo-Molina et al., 2018; Zacarias et al., 2019) or obesity prevalence (Balas-Nakash et al., 2010; Rios-Cortazar et al., 2013). Caballero-Garcia et al. (2017) was the only multi-site study (carried out in four different states of Mexico) and found that anthropometric changes varied depending on the site. Also, Costa-Urrutia et al. (2019) found that BMI decreased significantly depending on participants' baseline nutritional status and ethnicity.

Heterogeneity and inconsistency of results were also present when considering the different life stages. Weightrelated outcomes did not differ or were evident in preschool children, school-aged children, or adolescents.

\section{Dietary Outcomes}

Among the studies with a control group $(n=16)$, only nine measured dietary outcomes. Tools to measure dietary outcomes varied across studies, and not all were validated (Supplementary Information 2). In these studies, some dietary improvements were reported compared to the controls. For instance, some reported were fewer calories consumption (Alvirde-Garcia et al., 2013; Padilla-Raygoza et al., 2013), better-eating patterns (Ponce et al., 2016; Safdie et al., 2013a, b), increase in daily dairy consumption (Radilla-Vazquez et al., 2019) or reduce carbohydrates consumption (Alvirde-Garcia et al., 2013; Levy et al., 2012a, b) at the end of the study. Vega et al. (2019) reported a significant $(p<0.05)$ increase in fruit and vegetable consumption among the intervention group. However, this result varied according to their baseline nutritional status. Bacardi-Gascon and JiménezCruz (2012) reported an increased vegetable intake and decreased consumption of snacks containing fat and salt among the intervention group. Still, there was also a significant increase in sugar-sweetened beverages consumption among the intervention group compared with the control. Martinez-Andrade et al. (2014) found at three months a significant increase $(p<0.05)$ in vegetable consumption, significant reductions $(p<0.05)$ in sweet snacks and sugar added to drinks in the intervention group. However, intervention effects were attenuated at six months.

Among cohort studies ( $n=13)$, only 3/13 (23\%) studies measured dietary outcomes. Overall, significant improvements in dietary lifestyles were reported in these studies. Rodriguez-Ventura et al. (2018) reported that the frequency of unhealthy dietary patterns decreased, but only some (e.g., eating more fruits and vegetables and breakfast consumption) were significant $(p<0.05)$. Elizondo-Montemayor et al.
(2014) and Cruz-Bello et al. (2019) reported some significant $(p<0.05)$ dietary improvements (e.g., increase in the reported consumption of fruits and vegetables and decrease in soft drinks consumption). However, these studies also reported a decrease in the consumption of milk and water.

\section{Physical Activity and Sedentary Behaviours Outcomes}

Among the studies with a control group $(n=16)$, only $5 / 16$ (31.2\%) measured PA or sedentary outcomes. Tools to measure dietary outcomes varied across studies, and not all were reported as validated (Supplementary Information 2). Some studies reported statistically significant $(p<0.05)$ improvements compared to the controls, including a decrease in TV engagement (hr/day), sitting (hr/day), and an increased PA practice (Bacardi-Gascon \& Jiménez-Cruz 2012; GaticaDominguez et al., 2019; Macias et al., 2014). Levy et al., (2012a, b) reported more children to be active compared to controls. However, this was not reported as statistically significant $(p>0.05)$. Safdie et al. (2013a, b) reported that PA's increase among intervention groups (two different studies provided) vs control group was not significant. However, the step count was higher in one of the intervention groups than the other intervention and control groups.

Among cohort studies $(n=13)$, only 4/13 (30.7\%) measured PA or sedentary outcomes. Rodriguez-Ventura et al. (2018) reported only a statistically significant $(p<0.05)$ decrease in the time spent watching TV. Saucedo-Molina et al. (2018) reported a statistically significant $(p<0.05)$ increase in PA in the total sample. However, such an increase was higher among boys. Elizondo-Montemayor et al. (2014) reported no significant change in self-reported PA practice. Balas-Nakash et al. (2010), which implemented two different PA routines in two separate groups, reported that one group (routine B) registered higher PA levels; however, this result was not sustained six months follow-up.

\section{Quality and Risk of Bias Appraisal}

Only five (17.2\%) of the studies had an overall strong quality, $12(41.3 \%)$ a moderate quality, and $12(41.3 \%)$ a poor quality (Table 2). Overall, 16 (55.2\%) studies had a control group, and the study design was considered more robust than those without a control group. However, half of the studies with a control group (8/16) were randomised, and 2/8 RCTs were presented in an abstract. All except one were published in international journals or English language from the studies with the strongest quality. In most studies (79.8\%), participants were considered somewhat likely to represent the target population. Some studies (44.8\%) identified and controlled some analysis for relevant confounders. Because of the studies' nature, in most of the studies blinding was 


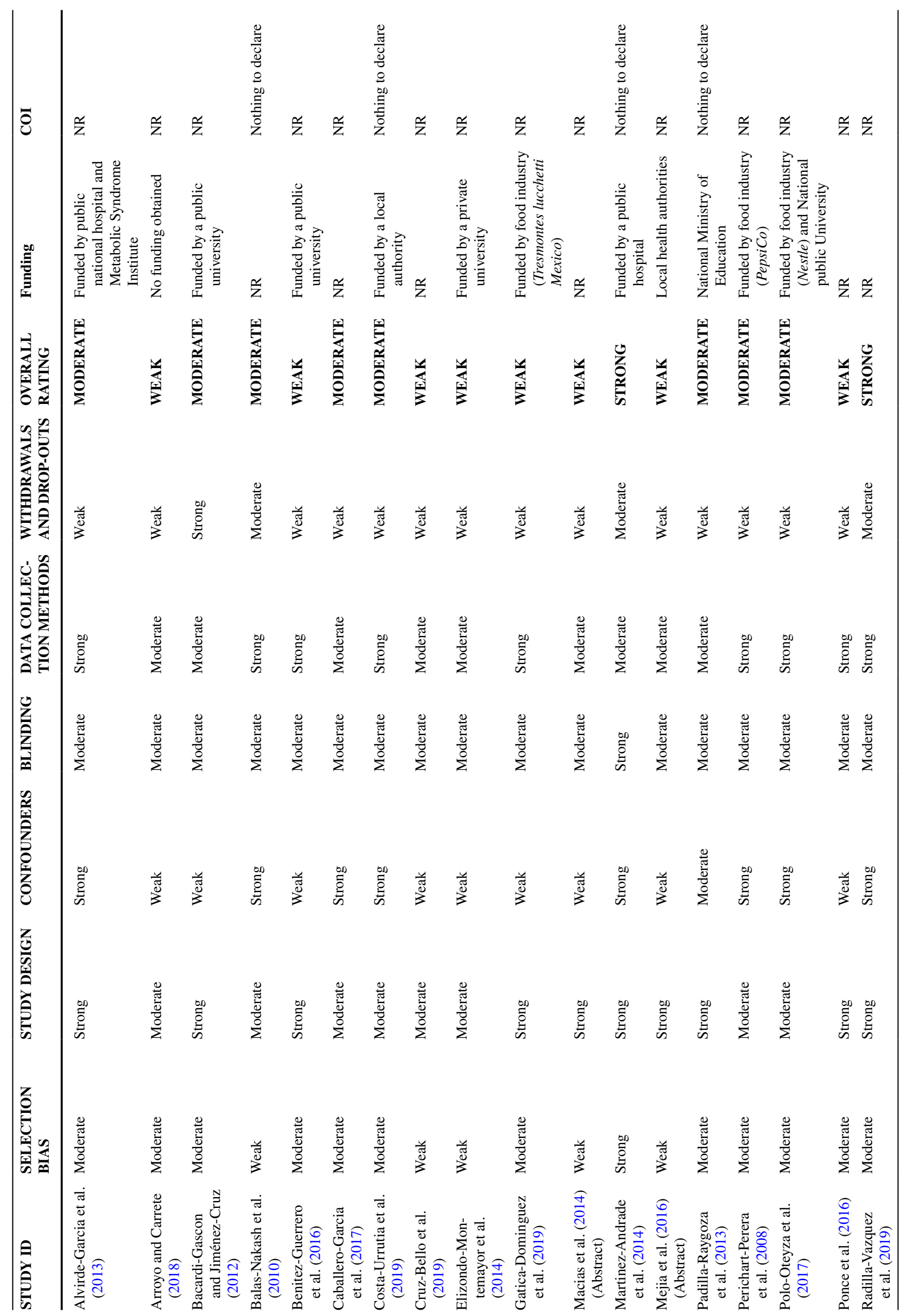




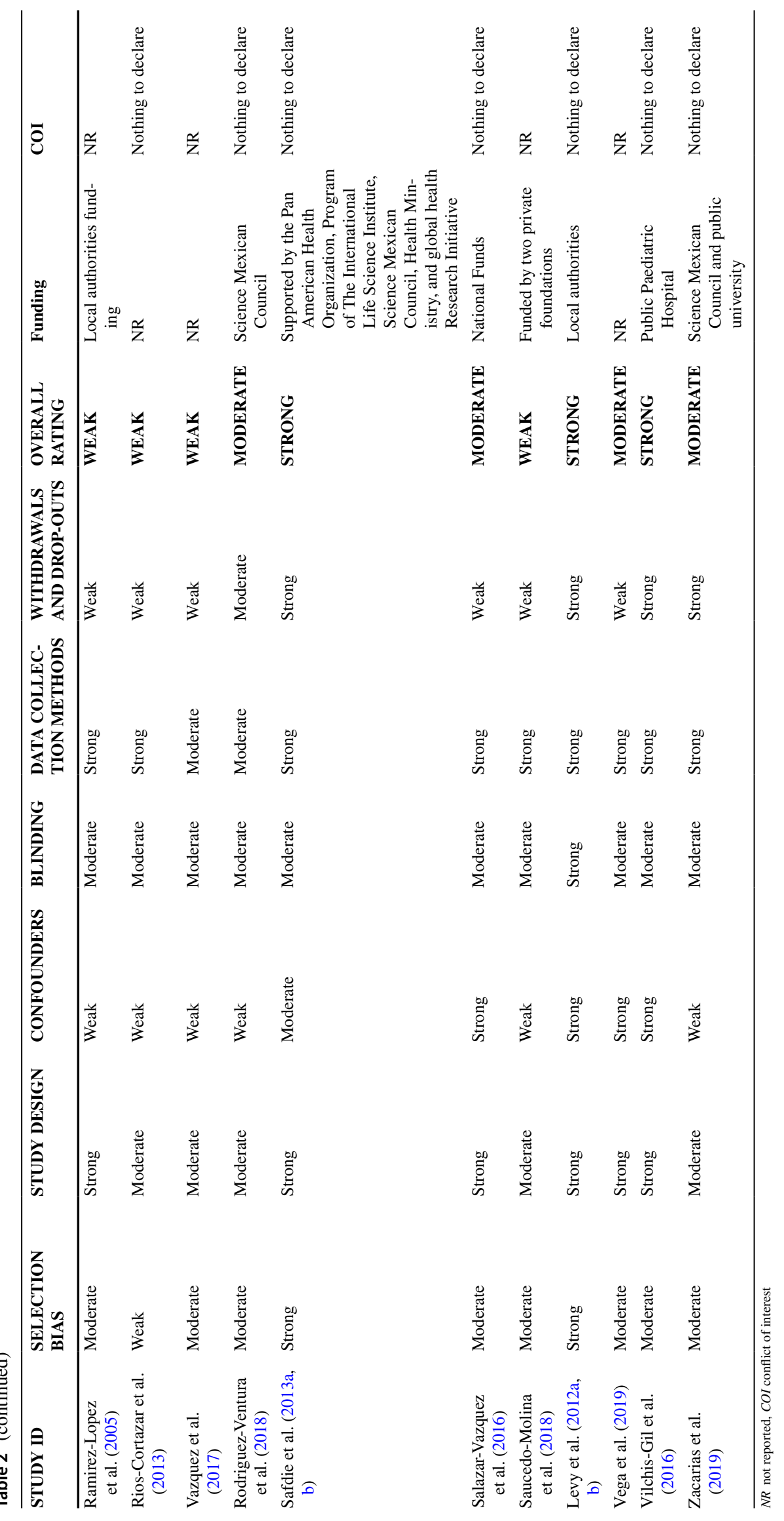


not described or considered. However, two (6.8\%) RCTs by Martinez-Andrade et al. (2014) and Levy et al. (2012a, b) described blinding as part of their methods. Data collection for anthropometric measurements did not raise any quality uncertainties since all the studies collected data according to international protocols. However, lifestyles outcome collection was very heterogeneous across studies. For instance, only 12 studies measured dietary lifestyles, and less than half of these were reported using validated tools (Supplementary Information 2). For studies measuring PA or sedentary lifestyles $(n=9)$, only six reported using validated tools, with only one specifically validated in Mexican children. Most studies $(20 ; 68.9 \%)$ had follow-up rates of less than $60 \%$. Only five studies (17.2\%) reported a follow-up rate of over $80 \%$. Very few studies $(4 ; 13.0 \%)$ reported using intentionto-treat in the analysis of their data. For details on each publication risk of bias assessment, see Table 2.

Concerning the studies' funding, nine (31.0\%) did not report any funding, and only one (Arroyo et al., 2018) reported not receiving any funding for the study. Three studies (10.3\%, Gatica-Dominguez et al., 2019; Perichart-Perera et al., 2008; Polo-Oteyza et al., 2017) reported receiving funding from the food industry, three more (10.3\%; Costa-Urrutia et al., 2019; Ramirez-Lopez et al., 2005; Levy et al., 2012a, b) reported using funds from local authorities. Five studies (17.2\%; Mejia et al., 2016; Padilla-Raygoza et al., 2013; Rodriguez-Ventura et al., 2018; Salazar-Vazquez et al., 2016; Zacarias et al., 2019) reported using public national funding, and five more (Alvirde-Garcia et al., 2013; Bacardi-Gascon \& JiménezCruz 2012; Benitez-Guerrero et al., 2016; Martinez-Andrade et al., 2014; Vilchis-Gil et al., 2016) received funding from public institutions (e.g., public hospitals or public universities). One study (Safdie et al., 2013a, b) reported being supported by local, national, and international organisations. Two (6.8\%; Elizondo-Montemayor et al., 2014; Saucedo-Molina et al., 2018) reported receiving funding from private institutions (e.g. private universities, insurance companies' funds). The authors' conflict of interest was not reported in 18 studies (62.0\%) (Table 2).

\section{Discussion}

This work systematically reviewed interventions to prevent obesity among children and adolescents in Mexico. Twentynine studies (presented in 43 publications) with various experimental designs, characteristics, duration, and intensities were identified after conducting a deep search across 13 databases and one search engine. Most studies (26; 89.6\%) included a nutritional component, $19(65.5 \%)$ a PA component, $12(41.0 \%)$ a behavioural or psychological component, and only six (20.7\%) included environmental changes to support obesity prevention and lifestyles improvement. Only three studies (10.3\%; Costa-Urrutia et al., 2019; Safdie et al., 2013a, b; Levy et al., 2012a, b) included several components. However, only one (Safdie et al., 2013a, 2013b) was implemented for over 12 months. Overall, very few studies $(17.2 \%)$ were considered to have a strong quality, and weight-related outcomes are heterogeneous across studies with or without a control group or age group. Some (12/29) measured dietary behaviours, with most showing dietary improvements. Fewer (9/29) measured and showed PA or sedentary lifestyle improvements.

The results shown in this review are like those presented in a recent systematic review of school-based obesity prevention interventions in Latin America (Chavez \& Nam, 2020). Some characteristics of the studies reported as effective align with previous children and adolescent's obesity prevention evidence. Long term and sustained ( $\geq 1$-school year) studies with multi-component studies seem to be more effective since single-component or short-term interventions have weaker evidence on obesity prevention (Summerbell et al., 2005). All the identified studies were delivered in a single set, with most $(26 ; 89.6 \%)$ delivered in schools. Schoolbased studies have been reported as effective in preventing obesity and improving lifestyles (Aceves-Martins et al., 2016b; Wang et al., 2015) However, the importance of multisetting interventions for childhood obesity prevention and treatment has also been acknowledged (Wang et al., 2015). Only six of the included studies in this review (20.7\%) reported changing the environment to reinforce healthy lifestyles and prevent obesity among participants, which has been recognised as an essential factor prevent or revert childhood obesity effectively (Cauchi et al., 2016).

Children's food choices might be influenced by observing and imitating others' behaviour, specifically parents or siblings (Mura Paroche et al., 2017). Some of the included studies in this review $(12 ; 41.3 \%)$ reported involving other family members in the intervention activities. Few studies $(9 ; 31.0 \%)$ were designed in the light of a model or behavioural theory. Behavioural change may happen because of alterations in variables that mediate risk factors. These mediating variables are typically considered in theories or models used to understand behaviour (Baranowski et al., 2003). Using theories or models in the design of childhood obesity prevention studies could be helpful. Understanding the environment, triggers of risk behaviours, and including close relatives in the activities might determine the effectiveness of childhood obesity prevention (Aceves-Martins et al., 2019; Loveman et al., 2015; Mura Paroche et al., 2017). The interventions' design and method might also be critical in behavioural change and health outcomes improvement. Most of the identified evidence refers to educational interventions (e.g., teaching children benefits healthy lifestyles). Knowledge at some level is a prerequisite to the intentional performance of health-related behaviours (Baranowski et al., 
2003). However, knowledge might not be enough to produce a behavioural change that prevents weight gain in the long term. For this reason, studies aiming a weight gain prevention should not be limited to educational activities.

Developing strategies to tackle childhood obesity is a complex task for different reasons: it involves several stakeholders, multiple environments need to be considered, different health risk behaviours need to be shaped, health inequalities need to be addressed, there is still an open scientific debate on the best way to address childhood obesity, and the socio-political, cultural or economic context is a critical factor that might influence the effective management of obesity (Gortmaker et al., 2015; Knai \& Mckee, 2010). Nevertheless, it is noteworthy that Mexico had led to implementing different nationwide strategies to tackle obesity among the general population. For instance, a couple of years ago, Mexico introduced a 1 peso per liter tax on sugar-sweetened beverages (Colchero et al., 2017; Mostert, 2017). More recently, a front-of-pack labelling law has also been introduced (Kaufer-Horwitz et al., 2018). Additionally, in 2017, the Caribbean Public Health Agency, the Pan American Health Organisation and the Caribbean Community brought together crucial stakeholders from Mexico and Chile to develop a roadmap to prevent childhood obesity (Caballero et al., 2017). Still, effective and targeted strategies are needed urgently to avoid and revert excess weight gain among children and adolescents.

A multi-component and multidisciplinary intervention that includes dietary modifications, physical activity practice, behavioural strategies, and active youth and parental involvement might help treat childhood obesity in Mexico (Aceves-Martins, 2021a, c, 2019). Indeed, these characteristics would also benefit prevention efforts. However, prevention would usually involve complex and multifaceted health promotion efforts at a community level, which cannot be expected to produce changes in outcomes within a short time frame, especially weight outcomes. Instead, a range of effects, including attitudes and health behaviours, can be achieved (Rosen et al., 2006), affecting weight outcomes in the long term. For this reason, longer-term measurements and follow-up of participants is needed.

Retrieved evidence arises from 13 (out of 32) states. As shown in Fig. 2, most evidence comes from Mexico's southcentral area. Caballero-Garcia et al. (2017) was the only multi-site study (including children from four different states of Mexico) and reported variability of the results depending on the site. For instance, BMI reduction was different across sites. The results of such a study are discussed, considering various difficulties of running a multi-state intervention in Mexico. It is unclear the reason for such disparity of interventions identified across the different country regions. However, a considerable amount of evidence (13/29) was identified in Mexico City (the capital) and the State of Mexico, two of the most densely populated areas in the country and several universities, speciality clinical centres, and research centres can be found. Efforts to identify vulnerable populations nationwide and implementation barriers among different populations are needed as a national strategy. Also, implementing long term nationwide studies that consider and include vulnerable children or adolescents from all the regions of Mexico is essential to change the upward trends in obesity prevalence.

We found some limitations and challenges while conducting this systematic review. One of the major problems faced was the inadequate and insufficient description of methods across the included studies. Also, the lack of high-quality RCTs is noticeable. Only 7/29 (24.1\%) studies were RCT and only three with strong quality. There is still a debate on the best ways to evaluate and assess the effectiveness of health promotion efforts (Rosen et al., 2006). No single method can be used to answer all relevant questions on health promotion or public health challenges (Armstrong et al., 2011). However, to evaluate the effectiveness of interventions, strong quantitative methods approaches are needed. Some suggest that randomised designs are appropriate for community-based health promotion research within the obesity prevention context (Rosen et al., 2006). Overall, the heterogeneity of the included studies, in terms of study design, sample size and characteristics, approach, follow-up length, analytical approach and overall quality of evidence, was also a limitation. The variability of these factors made not possible the effectiveness of cross-study comparison (i.e., meta-analysis), which is crucial for developing, evaluating, and improving studies, policies, practice, and research (Boaz \& Davies, 2019). Also, we limited this review to those studies considering weight outcomes. By using this criterion, we might have foreseen relevant efforts to change other lifestyles that might affect long term obesity prevention.

This work's strengths include being the first systematic review of intervention to prevent obesity in Mexican children and adolescents. An exhaustive search for evidence was done across 13 various databases and one search engine, performed in two languages, which helped us capture relevant publications. In addition, an extensive search for grey literature was conducted as part of the COMO project, but no relevant studies or interventions were identified. The characteristics of the included studies and quality appraisal were considered in the synthesis.

This review is part of a broader project aiming to synthesise and use data to comprehend the extent, nature, effects and costs of childhood or adolescent obesity in Mexico (Aceves-Martins, 2021a, b). Because of the rising levels of childhood and adolescent obesity, every effort should be considered an experiment. Effects must be documented and evaluated to benefit every other initiative or strategy. Such efforts need to enhance their methodological quality, include various settings, stakeholders, and target different health risk behaviours. 


\section{Conclusion}

Current evidence is heterogeneous and inconclusive about the efficacy of interventions to prevent obesity in Mexican children and adolescents. Overall, health promotion and prevention efforts need methodological improvement and should consider previous experiences to build evidence-based interventions. Such interventions should not be limited to educational activities and should include different components, such as multi-settings delivery, family inclusion, and longerterm implementations. Mixed-method evaluations (including strong quantitative and qualitative approaches) and follow up of participants after the intervention could provide a deeper understanding of the effectiveness and best practices.

Supplementary Information The online version contains supplementary material available at https://doi.org/10.1007/s11121-021-01316-6.

Funding No funding was received to do this work.

MA-M is currently funded by the Scottish Government's Rural and Environment Science and Analytical Services Division (RESAS).

\section{Declarations}

Ethics Approval and Consent to Participate Since this is a systematic review of published data, no ethical approval or consent to participate was required.

Conflict of Interest MA-M, LL-C, MG-B, and CFMG have no conflict of interest to declare. YYGG received funding from Bonafont to present in a congress in 2016 and funding from Abbott's company to write two books' chapters in 2020.

Open Access This article is licensed under a Creative Commons Attribution 4.0 International License, which permits use, sharing, adaptation, distribution and reproduction in any medium or format, as long as you give appropriate credit to the original author(s) and the source, provide a link to the Creative Commons licence, and indicate if changes were made. The images or other third party material in this article are included in the article's Creative Commons licence, unless indicated otherwise in a credit line to the material. If material is not included in the article's Creative Commons licence and your intended use is not permitted by statutory regulation or exceeds the permitted use, you will need to obtain permission directly from the copyright holder. To view a copy of this licence, visit http://creativecommons. org/licenses/by/4.0/.

\section{References}

Aburto, N. J., Fulton, J. E., Safdie, M., Duque, T., Bonvecchio, A. J. A. R., \& Rivera, J. A. (2011). Effect of a school-based intervention on physical activity: Cluster-randomised trial. Medicine and Science in Sports and Exercise, 43, 1898-1906. https://doi. org/10.1249/MSS.0b013e318217ebec

Aceves-Martins, M. (2021a). Perspectives of the "Childhood Obesity in MexicO: evidence, challenges and opportunities" (COMO) Project. Retrieved 03 March 2021. https://www.comoprojectmx. com/perspectives
Aceves-Martins, M., Aleman-Diaz, A. Y., Giralt, M., \& Solà, R. (2019). Involving young people in health promotion, research and policymaking: practical recommendations. International Journal for Quality in Health Care, 31(2), 147-53. https://doi.org/10. 1093/intqhe/mzy 113

Aceves-Martins, M., Godina-Flores, N. L., Gutierrez-Gómez, Y. Y., Richards, D., López-Cruz, L., García-Botello, M., \& Moreno-García, C. F. (2021b). Obesity and oral health in Mexican children and adolescents: systematic review and meta-analysis. Nutrition Reviews. https://doi.org/10.1093/nutrit/nuab088

Aceves-Martins, M., Llauradó, E., Tarro, L., Solà, R., \& Giralt, M. (2016a). Obesity-promoting factors in Mexican children and adolescents: Challenges and opportunities. Global Health Action, 9, 29625. https://doi.org/10.3402/gha.v9.29625

Aceves-Martins, M., Llauradó, E., Tarro, L., Moreno-García, C. F., Trujillo Escobar, T. G., Solà, R., \& Giralt, M. (2016b). Effectiveness of social marketing strategies to reduce youth obesity in European school-based interventions: a systematic review and metaanalysis.Nutrition Reviews, 74(5), 337-351. https://doi.org/ 10.1093/nutrit/nuw004

Aceves-Martins, M., López-Cruz, L., García-Botello, M., Gutierrez -Gómez, Y. Y., \& Moreno-García, C. F. (2021c). Interventions to treat obesity in mexican children and adolescents: systematic review and meta-analysis. https://doi.org/10.1093/nutrit/nuab041

Alvirde-García, U., Rodríguez-Guerrero, A. J., Henao-Morán, S., Gómez-Pérez, F. J., \& Aguilar-Salinas, C. A. (2013). Resultados de un programa comunitario de intervención en el estilo de vida en niños. Salud Pública De México, 55, 406-414.

Armstrong, R., Waters, E., \& Doyle., J. (2011). Reviews in public health and health promotion. Chapter 21. In: Higgins JPT, Green S, (eds). Cochrane Handbook for Systematic Reviews of Interventions. Version 5.1.0. Updated March 2011. London, UK.

Arroyo, P. E., \& Carrete, L. (2018). Intervención orientada a modificar prácticas alimentarias en adolescentes mexicanos. Gerencia y Políticas de Salud, 17(35).

Ash, T., Agaronov, A., Young, T., et al. (2017). Family-based childhood obesity prevention interventions: A systematic review and quantitative content analysis. International Journal of Behavioral Nutrition and Physical Activity, 14, 113. https://doi.org/10.1186/ s12966-017-0571-2

Astudillo, O. (2014). Country in Focus: Mexico's growing obesity problem. The Lancet Diabetes \& Endocrinology, 2, 15-16. https:// doi.org/10.1016/S2213-8587(13)70160-8

Bacardí-Gascon, M., \& Jiménez-Cruz, A. (2012). A six month randomised school intervention and an 18-month follow-up intervention to prevent childhood obesity in Mexican elementary schools. Nutricion Hospitalaria, 27, 755-762.

Balas-Nakash, M., Benítez-Arciniega, A., Perichart-Perera, O., ValdésRamos, R., \& Vadillo-Ortega, F. (2010). The effect of exercise on cardiovascular risk markers in Mexican school-aged children: Comparison between two structured group routines. Salud Publica De Mexico, 52, 398-405.

Baranowski, T., Cullen, K. W., Nicklas, T., Thompson, D., \& Baranowski, J. (2003). Are current health behavioral change models helpful in guiding prevention of weight gain efforts? Obesity Research, 11, 23S-43S. https://doi.org/10.1038/oby.2003.222

Benítez-Guerrero, V., de Jesús Vázquez-Arámbula, I., Sánchez-Gutiérrez, R., Velasco-Rodríguez, R., Ruiz-Bernés, S., \& de Jesús MedinaSánchez, M. (2016). Intervención educativa en el estado nutricional y conocimiento sobre alimentación y actividad física en escolares. Revista De Enfermería Del Instituto Mexicano Del Seguro Social, 24, 37-43.

Boaz, A., \& Davies, H. (2019). (Eds.) What works now?: evidenceinformed policy and practice. Policy Press. 
Bonvecchio, A., Théodore, F. L., Safdie, M., Duque, T., Villanueva, M. Á., Torres, C., \& Rivera, J. (2014). Contribution of formative research to design an environmental program for obesity prevention in schools in Mexico City. Salud Pública De México, 56, 139-147.

Bonvecchio-Arenas, A., Theodore, F. L., Hernández-Cordero, S., Campirano-Núñez, F., Islas, A. L., Safdie, M., \& RiveraDommarco, J. A. (2010). La escuela como alternativa en la prevención de la obesidad: La experiencia en el sistema escolar mexicano. Revista Española De Nutrición Comunitaria, $16,13-16$.

Caballero, B., Vorkoper, S., Anand, N., \& Rivera, J. A. (2017). Preventing childhood obesity in Latin America: An agenda for regional research and strategic partnerships. Obesity Reviews, 18, 3-6. https://doi.org/10.1111/obr.12573

Caballero-García, C. R., Flores-Alatorre, J. F., Bonilla-Fernández, P., \& Arenas-Monreal, L. (2017). Experiencias de promoción de la salud en escuelas de nivel primario en México. Memorias del Instituto de Investigaciones en Ciencias de la Salud (Impr.), 22-32.

Cauchi, D., Glonti, K., Petticrew, M., \& Knai, C. (2016). Environmental components of childhood obesity prevention interventions: An overview of systematic reviews. Obesity Reviews, 17, 1116-1130. https://doi.org/10.1111/obr.12441

Cespedes, E., Andrade, G. O. M., Rodríguez-Oliveros, G., Perez-Cuevas, R., González-Unzaga, M. A., Trejo, A. B., \& Taveras, E. M. (2012). Opportunities to strengthen childhood obesity prevention in two mexican health care settings. International Journal of Person Centered Medicine, 2, 496.

Chavez, R. C., \& Nam, E. W. (2020). School-based obesity prevention interventions in Latin America: a systematic review. Revista de Saude Publica, 54, 110. https://doi.org/10.11606/s1518-8787. 2020054002038

Colchero, M. A., Rivera-Dommarco, J., Popkin, B. M., \& Ng, S. W. (2017). In Mexico, evidence of sustained consumer response two years after implementing a sugar-sweetened beverage tax. Health Affairs, 36, 564-571. https://doi.org/10.1377/hlthaff.2016.1231

Costa-Urrutia, P., Álvarez-Fariña, R., Abud, C., Franco-Trecu, V., Esparza-Romero, J., López-Morales, C. M., \& Granados, J. (2019). Effect of multi-component school-based program on body mass index, cardiovascular and diabetes risks in a multiethnic study. BMC Pediatrics, 19, 1-9. https://doi.org/10.1186/ s12887-019-1787-x

Cruz-Bello, P., Martínez-Garduño, M. D., Olivos-Rubio, M., JiménezVargas, D., \& De la Cruz-Martínez, A. (2019). Mejora del conocimiento y conducta alimentaria de los adolescentes con una intervención educativa basada en orientación alimentaria. Revista De Enfermería Del Instituto Mexicano Del Seguro Social, 26(4), 248-255.

Elizondo-Montemayor, L., Gutiérrez, N. G., Moreno Sánchez, D. M., Monsiváis Rodríguez, F. V., Martínez, U., Nieblas, B., \& LamadridZertuche, A. C. (2014). Intervención para promover hábitos saludables y reducir obesidad en adolescentes de preparatoria. Estudios Sociales (Hermosillo, Son.), 22(43), 217-239.

ENSANUT [Encuesta Nacional de Salud y Nutrición 2018]. (2018). Presentacion de resultados. Retrieved 03 March 2021. https://ensanut. insp.mx/encuestas/ensanut2018/doctos/informes/ensanut_2018_ presentacion_resultados.pdf

EPHPP [Effective Public Health Practice Project]. (2010). Quality Assessment Tool For Quantitative Studies. Hamilton, ON: Effective Public Health Practice Project. Retrieved 24 June 2020 https:// merst.ca/ephpp/

Garduño-Espinosa, J., Morales-Cisneros, G., Martínez-Valverde, S., Contreras-Hernández, I., Flores-Huerta, S., Granados-García, V., \& Muñoz-Hernández, O. (2008). Una mirada desde los servicios de salud a la nutrición de la niñez mexicana: III. Carga económica y en salud de la obesidad en niños mexicanos. Proyecciones de largo plazo. Boletín médico del Hospital Infantil de México, 65(1), 49-56.
Gatica-Domínguez, G., Moreno-Saracho, J. E., Cortés, J. D., HenaoMoran, S. A., \& Rivera, J. A. (2019). Condición física de escolares tras intervención educativa para prevenir obesidad infantil en Morelos, México. Salud Pública De México, 61, 78-85.

Global Obesity Observatory. (2019). Map Overview of childhood obesity. Retrieved 03 March 2021. https://www.worldobesitydata.org/ map/overview-children

Gortmaker, S. L., Wang, Y. C., Long, M. W., Giles, C. M., Ward, Z. J., Barrett, J. L., \& Cradock, A. L. (2015). Three interventions that reduce childhood obesity are projected to save more than they cost to implement. Health Affairs, 34, 1932-1939. https://doi.org/10. 1377/hlthaff.2015.0631

Green, C., Auguste, P. E., Lloyd, J. L., \& Wyatt, K. M. (2012). Modelling of future outcomes to estimate the cost effectiveness of interventions related to child and adolescent overweight and obesity. The Lancet, 380, S43. https://doi.org/10.1016/S0140-6736(13)60399-2

Kaufer-Horwitz, M., Tolentino-Mayo, L., Jauregui, A., Sánchez-Bazán, K., Bourges, H., Martínez, S., \& Barquera, S. (2018). A frontof-pack labelling system for food and beverages for Mexico: A strategy of healthy decision-making. Salud Publica De Mexico, $60,479-486$.

Knai, C., \& McKee, M. (2010). Tackling childhood obesity: the importance of understanding the context. Journal Of Public Health, 32(4), 506-511.https://doi.org/10.1093/pubmed/fdq019

Levy, T. S., del Carmen Morales-Ruan, M., Castellanos, C. A., Coronel, A. S., Aguilar, A. J., \& Humarán, I. M. G. (2012a). School environment and its relationship with obesity in the state of Mexico. The FASEB Journal. 26(suppl 629.9).

Levy, T. S., Izeta, E. I. E., Ruan, C. M., Castellanos, C. A., \& Coronel, A. S. (2011). Efficacy of a strategy of school children's feeding and physical activity behaviors related to overweight and obesity in Mexico. Federation of American Societies. NR,594-12.

Levy, T. S., Ruán, C. M., Castellanos, C. A., Coronel, A. S., Aguilar, A. J., \& Humarán, I. M. G. (2012b). Effectiveness of a diet and physical activity promotion strategy on the prevention of obesity in Mexican school children. BMC Public Health, 12, 1-13. https:// doi.org/10.1186/1471-2458-12-152

Liu, Z., Xu, H. M., Wen, L. M. et al. (2019). A systematic review and meta-analysis of the overall effects of school-based obesity prevention interventions and effect differences by intervention components. International Journal of Behavioral Nutrition and Physical Activity, 16, 95. https://doi.org/10.1186/s12966-019-0848-8

Loveman, E., Al-Khudairy, L., Johnson, R. E., Robertson, W., Colquitt, J. L., Mead, E. L., \& Rees, K. (2015). Parent-only interventions for childhood overweight or obesity in children aged 5 to 11 years. Cochrane Database of Systematic Reviews, (12). https://doi.org/ 10.1002/14651858.CD012008

Macias, M., Avila-Huerta, C., De la Roca-Chiapas, J., \& GaraySevilla, M. (2014). PS-344 Effectiveness Of Program "5 Steps For Health" In Scholar Children In Mexico"Archives of Disease in Childhood, 99, A236. https://doi.org/10.1136/archdischild-2014307384.643

Martínez-Andrade, G. O., Cespedes, E. M., Rifas-Shiman, S. L., Romero-Quechol, G., González-Unzaga, M. A., Benítez-Trejo, M. A., \& Gillman, M. W. (2014). Feasibility and impact of Creciendo Sanos, a clinic-based pilot intervention to prevent obesity among preschool children in Mexico City. BMC Pediatrics, 14, 1-15. https://doi.org/10.1186/1471-2431-14-77

Mejia, M. A., Coria-Navia, A., Uriegas-Mejia, G., Brown-Fraser, S., Uriegas, S. E., Martinez, M. D. J., \& Sanchez, A. (2016). D-2 The Victoria Trial: a school-based health education program to reduce the risk of obesity among a high-risk population. The FASEB Journal, 31, 6411-6411. https://doi.org/10.1096/fasebj. 31.1_supplement.641.1

Morales-Ruán, M. D. C., Shamah-Levy, T., Amaya-Castellanos, C. I., Salazar-Coronel, A. A., Jiménez-Aguilar, A., Amaya-Castellanos, 
M. A., \& Méndez-Gómez Humarán, I. (2014). Effects of an intervention strategy for school children aimed at reducing overweight and obesity within the State of Mexico. Salud Pública De México, 56, s113-s122.

Mostert, C. M. (2017). Sugar-sweetened beverage tax in Mexico. Health Affairs, 36, 1144-1144. https://doi.org/10.1377/hlthaff. 2017.0483

Mura Paroche, M., Caton, S. J., Vereijken, C. M., Weenen, H., \& Houston-Price, C. (2017). How infants and young children learn about food: A systematic review. Frontiers in Psychology, 8, 1046. https://doi.org/10.3389/fpsyg.2017.01046

OECD [Organisation for Economic Co-operation and Development] (2017). Obesity Update 2017 Retrieved 01 March 2021. https:// www.oecd.org/els/health-systems/Obesity-Update-2017.pdf

Ortega-Cortés, R. (2014). Costos económicos de la obesidad infantil y sus consecuencias. Revista Médica Del Instituto Mexicano Del Seguro Social, 52, 8-11.

Padilla-Raygoza, N., Diaz-Guerrero, R., \& Ruiz-Paloalto, M. L. (2013). Lifestyle intervention as a treatment for obesity among schoolage-children in Celaya, Guanajuato: An experimental study. Central Asian Journal of Global Health, 2, 21. https://doi.org/ 10.5195/cajgh.2013.21

Palacios-González, B., Vadillo-Ortega, F., Polo-Oteyza, E., Sánchez, T., Ancira-Moreno, M., Romero-Hidalgo, S., \& Antuna-Puente, B. (2015). Irisin levels before and after physical activity among school-age children with different BMI: A direct relation with leptin. Obesity, 23, 729-732. https://doi.org/10.1002/oby.21029

Perez-Morales, M., Bacardí-Gascón, M., \& Jiménez-Cruz, A. (2011). Long-term randomized school-based intervention: effect on obesity and lifestyles in Mexico: T1: P. 039. Obesity Reviews, 12.

Perichart-Perera, O., Balas-Nakash, M., Ortiz-Rodríguez, V., MoránZenteno, J. A., Guerrero-Ortiz, J. L., \& Vadillo-Ortega, F. (2008). Programa para mejorar marcadores de riesgo cardiovascular en escolares mexicanos. Salud Pública De México, 50(3), 218-226.

Polo-Oteyza, E., Ancira-Moreno, M., Rosel-Pech, C., Sanchez-Mendoza, M. T., Salinas-Martínez, V., \& Vadillo-Ortega, F. (2017). An intervention to promote physical activity in Mexican elementary school students: Building public policy to prevent noncommunicable diseases. Nutrition Reviews, 75, (suppl_1), 70-78.

Ponce, G., de León, P., Campoy, U. R., Bravo, A. C., \& Rosas, A. M. (2016). Impacto de un programa de promoción de alimentación saludable en el IMC y en los hábitos de alimentación en alumnos de educación secundaria. Revista Iberoamericana De Las Ciencias De La Salud: RICS, 5, 7.

PRISMA [Preferred Reporting Items for Systematic Reviews and MetaAnalyses]. (2021). http://prisma-statement.org/

PROSPERO. (2021). [International prospective register of systematic reviews]. Registered on 23 October 2019, https://www.crd.york. ac.uk/prospero

Radilla Vázquez, C. C., Gutiérrez Tolentino, R., \& Vega y León, S., Radilla Vázquez, M., Coronado Herrera, M., \& Muro Delgado, R. D. (2019). Intervención para el fomento del consumo de leche y productos lácteos como parte de una estrategia para la disminución del exceso de peso en adolescentes de la Ciudad de Mexico. Nutrición Hospitalaria, 36, 526-537.

Ramírez-López, E., Grijalva-Haro, M. I., Valencia, M. E., Ponce, J. A., \& Artalejo, E. (2005). Impacto de un programa de desayunos escolares en la prevalencia de obesidad y factores de riesgo cardiovascular en niños sonorenses. Salud Pública De México.

Ríos-Cortázar, V., Gasca-García, A., Ordóñez, A. R., Vera, M. E., Franco-Martínez, M., \& Tolentino-Mayo, L. (2013). Reducción de la obesidad infantil a través del componente de nutrición de una iniciativa de Escuela Promotora de Salud. Salud Pública De México, 55, 431-433.
Rodríguez-Ventura, A. L., Pelaez-Ballestas, I., Sámano-Sámano, R., Jimenez-Gutierrez, C., \& Aguilar-Salinas, C. (2014). Barriers to lose weight from the perspective of children with overweight/ obesity and their parents: A sociocultural approach. Journal of Obesity, 2014, 7. https://doi.org/10.1155/2014/575184

Rodriguez-Ventura, A., Parra-Solano, A., Illescas-Zárate, D., HernándezFlores, M., Paredes, C., Flores-Cisneros, C., et al. (2018). "Sacbe", a comprehensive intervention to decrease body mass index in children with adiposity: A pilot study. International Journal of Environmental Research and Public Health, 15, 2010. https://doi.org/10.3390/ ijerph15092010

Rosen, L., Manor, O., Engelhard, D., \& Zucker, D. (2006). In defense of the randomised controlled trial for health promotion research. American Journal of Public Health, 96, 1181-1186. https://doi. org/10.2105/AJPH.2004.061713

Safdie, M., Cargo, M., Richard, L., \& Lévesque, L. (2014). An ecological and theoretical deconstruction of a school-based obesity prevention program in Mexico. International Journal of Behavioral Nutrition and Physical Activity, 11, 1-10. https://doi.org/ 10.1186/s12966-014-0103-2

Safdie, M., Jennings-Aburto, N., Lévesque, L., Janssen, I., CampiranoNúñez, F., López-Olmedo, N., \& Rivera, J. A. (2013a). Impact of a school-based intervention program on obesity risk factors in Mexican children. Salud Pública De México, 55, 374-387.

Safdie, M., Lévesque, L., González-Casanova, I., Salvo, D., Islas, A., Hernández-Cordero, S., \& Rivera, J. A. (2013b). Promoting healthful diet and physical activity in the Mexican school system for the prevention of obesity in children. Salud Pública De México, 55, 357-373.

Salazar Vázquez, B. Y., Salazar Vazquez, M. A., López Gutiérrez, G., Acosta Rosales, K., Cabrales, P., Vadillo-Ortega, F., \& SchmidSchönbein, G. W. (2016). Control of overweight and obesity in childhood through education in meal time habits. the "good manners for a healthy future"programme. Pediatric Obesity, 11(6), 484-490. https://doi.org/10.1111/ijpo.12091

Saucedo-Molina, T. D. J., Villarreal Castillo, M., Oliva Macías, L. A., Unikel Santoncini, C., \& Guzmán Saldaña, R. M. E. (2018). Disordered eating behaviours and sedentary lifestyle prevention among young Mexicans: A pilot study. Health Education Journal, 77, 872-883. https://doi.org/10.1177/0017896918782279

Summerbell, C. D., Waters, E., Edmunds, L., Kelly, S. A., Brown, T., \& Campbell, K. J. (2005). Interventions for preventing obesity in children. Cochrane Database Of Systematic Reviews, (3).

Tamayo, M. C., Dobbs, P. D., \& Pincu, Y. (2021). Family-centered interventions for treatment and prevention of childhood obesity in hispanic families: A systematic review. Journal of Community Health, 46, 635-643. https://doi.org/10.1007/s10900-020-00897-7

TIDieR. (2021). Template for intervention description and replication checklist. Retrieved 24 June 2020. https://www.equator-network. org/reporting-guidelines/tidier/

Vázquez, P. R., García, R. I. C., De la Rosa Rodríguez, C., Mata, F. E. C., \& Guzmán, G. M. (2017). Intervención educativa nutricional por enfermería en adolescentes con obesidad y sobrepeso en una escuela pública de Ciudad Victoria. Revista Salud Pública y Nutrición, 15(3), 28-34.

Vega, S., León, C. C. R. V., Tolentino, R. G., \& Radilla, M. J. R. E. N. C. (2019). Intervención para la incentivación del consumo de verduras y frutas como estrategia para la disminución del exceso de peso en adolescentes de la Ciudad de México. Revista Española de Nutrición Comunitaria, 25(1).

Vilchis-Gil, J., Klünder-Klünder, M., \& Flores-Huerta, S. (2018). Effect on the metabolic biomarkers in schoolchildren after a comprehensive intervention using electronic media and in-person ses- 
sions to change lifestyles: Community trial. Journal of Medical Internet Research, 20, e44. https://doi.org/10.2196/jmir.9052

Vilchis-Gil, J., Klünder-Klünder, M., Duque, X., \& Flores-Huerta, S. (2016). Decreased body mass index in schoolchildren after yearlong information sessions with parents reinforced with web and mobile phone resources: Community trial. Journal of Medical Internet Research, 18, e174. https://doi.org/10.2196/jmir.5584

Wang, Y., \& Lim, H. (2012). The global childhood obesity epidemic and the association between socio-economic status and childhood obesity. International Review of Psychiatry, 24, 176-188. https:// doi.org/10.3109/09540261.2012.688195

Wang, Y., Cai, L., Wu, Y., Wilson, R. F., Weston, C., Fawole, O., \& Segal, J. (2015). What childhood obesity prevention programmes work? A systematic review and meta-analysis. Obesity Reviews, 16, 547-565. https://doi.org/10.1111/obr.12277

Ward, D. S., Welker, E., Choate, A., Henderson, K. E., Lott, M., Tovar, A., Wilson, A., \& Sallis, J. F. (2017). Strength of obesity prevention interventions in early care and education settings: A systematic review. Preventive Medicine, 95, S37-S52. https://doi. org/10.1016/j.ypmed.2016.09.033

WHO [World Health Organisation]. (2012). Population-based approaches to childhood obesity prevention. Retrieved 01 March 2021. https://www.who.int/dietphysicalactivity/childhood/ WHO_new_childhoodobesity_PREVENTION_27nov_HR_ PRINT_OK.pdf

Zacarías, G., Shamah-Levy, T., Elton-Puente, E., Garbus, P., \& García, O. P. (2019). Development of an intervention program to prevent childhood obesity targeted to Mexican mothers of school-aged children using intervention mapping and social cognitive theory. Evaluation and Program Planning, 74, 27-37. https://doi.org/10. 1016/j.evalprogplan.2019.02.008

Publisher's Note Springer Nature remains neutral with regard to jurisdictional claims in published maps and institutional affiliations. 